\title{
HNF4 $\alpha$ isoforms regulate the circadian balance between carbohydrate and lipid metabolism in the liver
}

\begin{abstract}
Jonathan R. Deans ${ }^{1,2}$, Poonamjot Deol ${ }^{1 *}$, Nina Titova ${ }^{1 *}$, Sarah H. Radi ${ }^{1,3 *}$, Linh M. Vuong ${ }^{1 *}$, Jane R. Evans ${ }^{1}$, Songqin Pan ${ }^{4}$, Johannes Fahrmann ${ }^{5 a}$, Jun Yang ${ }^{6}$, Bruce D. Hammock ${ }^{6}$, Oliver Fiehn $^{5}$, Baharan Fekry ${ }^{7}$, Kristin Eckel-Mahan ${ }^{7,8}$ and Frances M. Sladek ${ }^{1 \#}$
\end{abstract}

${ }^{1}$ Department of Molecular, Cell and Systems Biology, ${ }^{2}$ Genetics, Genomics and Bioinformatics Graduate Program, ${ }^{3}$ Biochemistry and Molecular Biology Graduate Program, ${ }^{4}$ Proteomics Core, Institute for Integrative Genome Biology, University of California Riverside, Riverside, California 92521, USA

${ }^{5}$ National Institutes of Health West Coast Metabolomics Center, ${ }^{6}$ Department of Entomology and Nematology \& UCD Comprehensive Cancer Center, University of California, Davis, CA, 95616, USA

${ }^{7}$ Department of Biochemistry and Molecular Biology, ${ }^{8}$ Institute of Molecular Medicine, McGovern Medical School at the University of Texas Health Science Center (UT Health), Houston Texas 77030, USA

${ }^{a}$ Current address: Red and Charline McCombs Institute for the Early Detection and Treatment of Cancer, University of Texas, M.D. Anderson

*Contributed equally

\# Corresponding author:

Frances M Sladek, Ph.D.

Professor of Cell Biology and Toxicologist 4140 Multidisciplinary Research Building University of California, Riverside Frances.sladek@ucr.edu Tel: (951) 827-2264/Fax: (951) 827-3087 


\begin{abstract}
Hepatocyte Nuclear Factor $4 \alpha(\mathrm{HNF} 4 \alpha)$, a master regulator of hepatocyte differentiation, is regulated by two promoters ( $\mathrm{P} 1$ and $\mathrm{P} 2) . \mathrm{P} 1-\mathrm{HNF} 4 \alpha$ is the major isoform in the adult liver while P2-HNF4 $\alpha$ is thought to be expressed only in fetal liver and liver cancer. Here, we show that P2$\mathrm{HNF} 4 \alpha$ is expressed at ZT9 and ZT21 in the normal adult liver and orchestrates a distinct transcriptome and metabolome via unique chromatin and protein-protein interactions. We demonstrate that while P1-HNF4 $\alpha$ drives gluconeogenesis, P2-HNF4 $\alpha$ drives ketogenesis and is required for elevated levels of ketone bodies in females. Exon swap mice expressing only P2HNF4 $\alpha$ exhibit subtle differences in circadian gene regulation and disruption of the clock increases expression of P2-HNF4 $\alpha$. Taken together, we propose that the highly conserved twopromoter structure of the Hnfa gene is an evolutionarily conserved mechanism to maintain the balance between gluconeogenesis and ketogenesis in the liver in a circadian fashion.
\end{abstract}

Keywords: nuclear receptor, alternative promoter, ketogenesis, circadian clock, fasting, sexspecific gene expression, metabolic switch, cytochrome P450 


\section{Introduction}

Roughly $30 \%$ of human genes contain alternative promoters and yet the functional significance of the majority of those promoters, and the transcripts they generate, is woefully understudied. One such gene is the nuclear receptor (NR) Hepatocyte Nuclear Factor 4 alpha $(\mathrm{HNF} 4 \alpha)$, a liver-enriched transcription factor (TF) best known as a master regulator of liverspecific gene expression and mutated in Maturity Onset Diabetes of the Young 1 (MODY1) (Sladek et al., 1990) (Lu, 2016). In mouse, HNF4 $\alpha$ is essential for fetal liver function (Battle et al., 2006) and liver knockout (KO) mice die within six weeks of birth with a fatty liver (Hayhurst et al., 2001).

The human $H N F 4 A$ and mouse Hnf4a genes are highly conserved and regulated by proximal P1 and distal P2 promoters. P1 drives the expression of transcripts containing exon 1A while P2 transcripts contain exon 1D, resulting in a loss of the N-terminal activation function 1 (AF-1). In the adult liver $\mathrm{P} 1$ is presumed to be the only active promoter, while during fetal liver development both P1 and P2 are active (Briançon et al., 2004; Torres-Padilla et al., 2001). The first P2-HNF4 $\alpha$ transcript cloned, HNF4 $\alpha$ 7, was from the embryonal carcinoma cell line F9 (Nakhei et al., 1998), suggesting that it might play a role in cancer as well as fetal development. $\mathrm{P} 1-\mathrm{HNF} 4 \alpha$ is down regulated in liver cancer and acts as a tumor suppressor (Hatziapostolou et al., 2011; Ning et al., 2010; Tanaka et al., 2006; Walesky and Apte, 2015), while overexpression of P2-HNF4 $\alpha$ is linked to poor prognosis in hepatocellular carcinoma (HCC) (Cai et al., 2017).

To address the physiological role of P2-HNF4 $\alpha$, we employed exon swap mice ( $\alpha 7 \mathrm{HMZ}$ ), which substitute exon 1A with exon 1D in the P1 promoter and demonstrate a subtle, albeit illdefined role for the AF-1 domain in vivo (Briançon and Weiss, 2006). We compared the $\alpha 7 \mathrm{HMZ}$ adult mice (express only P2-HNF4 $\alpha$ ) to wildtype (WT) mice (express P1-HNF4 $\alpha$ ) using RNA- 
seq, ChIP-seq, rapid immunoprecipitation mass spectrometry of endogenous proteins (RIME), protein binding microarrays (PBMs) and metabolomics. An orchestrated, altered hepatic transcriptome in P2-HNF4 $\alpha$ livers reveals notable differences in cytochrome P450 transcripts and subtle differences in the hepatic circadian clock, as well as an apparent feminization of male livers. The distinct P2-HNF4 $\alpha$ transcriptome appears to be due to altered protein-protein interactions, as well as altered chromatin binding but not differences in innate DNA binding specificity. Expression of P2-HNF4 $\alpha$ is observed at Zeitgeber time (ZT) 9 and ZT 21 in WT adult livers, and is upregulated in Clock-deficient mice. The P2-HNF4 $\alpha$ hepatic metabolome is enriched in lipids and ketone bodies while mice expressing only P1-HNF4 $\alpha$ exhibit enhanced gluconeogenesis and lack the elevated levels of ketone bodies normally found in females. Taken together, our results suggest that expression of $\mathrm{P} 2-\mathrm{HNF} 4 \alpha$ in the liver is an evolutionarily conserved mechanism to balance carbohydrate and fatty acid metabolism during the circadian cycle.

\section{Results}

\section{The P2-HNF4a transcriptome has neither a fetal nor a cancer profile}

Exon swap $\alpha 7 \mathrm{HMZ}$ mice were verified to express P2-HNF4 $\alpha$, but not P1-HNF4 $\alpha$, RNA and protein in adult liver (Figures 1A-1C). RNA-seq of adult male livers revealed a significant difference (padj $\leq 0.01$ ) in $\sim 1600$ genes between WT and $\alpha 7 \mathrm{HMZ}$, both up- (831) and downregulated (792) in $\alpha 7 \mathrm{HMZ}$ (Figure 1D). The most downregulated (e.g., Scnn1a, Cyp2c50, Rdh16f2, Ces2e) and upregulated genes (e.g., Rad51b, Pcp4l1, Cyp2b13, Cyp2b9) exhibited up nearly 30-fold effects (Figure 1E). Kegg pathway analysis revealed discrete metabolic pathways in $\alpha 7 \mathrm{HMZ}$ versus WT livers, suggesting a purposeful alteration in gene expression (Figure 1F). 
For example, cell adhesion molecules, drug and linoleic acid metabolism and steroid hormone biosynthesis genes were enriched in WT mice while the ribosome, oxidative phosphorylation and RNA transport and processing were enriched in $\alpha 7 \mathrm{HMZ}$. Several disease pathways were also enriched among the P2-specific genes, including non-alcoholic fatty liver disease (NAFLD), viral carcinogenesis, alcoholism and neurological diseases (Parkinson's, Huntington's, Alzheimer's) (Figure 1F). Comparison of $\alpha 7 \mathrm{HMZ}$ versus WT differentially expressed genes (DEGs) with HNF4 $\alpha$ liver KO expression data (Walesky et al., 2013) revealed that $\sim 100$ of the WT-specific genes (but none of the $\alpha 7 \mathrm{HMZ}$-specific genes) were downregulated in the HNF4 $\alpha$ KO (Figure S1A), confirming P1-HNF4 $\alpha$ predominance in the adult liver.

The $\alpha 7 \mathrm{HMZ}$ versus WT DEGs were compared with adult versus fetal (E14.5) liver DEGs (Figure 1G). More than two thirds of the genes upregulated in WT livers were also upregulated in the adult liver, while $\sim 10 \%$ were enriched in fetal livers (562 versus 87 , respectively). In contrast, $\alpha 7 \mathrm{HMZ}$-upregulated genes were more evenly split between adult and fetal liver (Figure $1 G)$. Interestingly, alpha-fetoprotein $(A f p)$ and other fetal liver genes were expressed at a lower level in $\alpha 7 \mathrm{HMZ}$ (Figure S1B), suggesting that the $\alpha 7 \mathrm{HMZ}$ "program" is not simply a fetal one. Furthermore, while $\alpha 7 \mathrm{HMZ}$ mice have a significantly $(\mathrm{p}<0.01)$ higher liver-to-body weight ratio than WT or $\alpha 1 \mathrm{HMZ}$ (exon 1A swapped for exon 1D in the P2 promoter) at postnatal day 14 , the reverse $(\alpha 1 \mathrm{HMZ}>\alpha 7 \mathrm{HMZ}$ ) is observed at postnatal day 21 (Figure S1C). Finally, proliferation genes Mki67 and Pcna were not upregulated in $\alpha 7 \mathrm{HMZ}$ adult livers as one might anticipate for a predominantly fetal TF (Figure S1E).

To determine whether $\alpha 7 \mathrm{HMZ}$ livers exhibit a cancer profile, the $\alpha 7 \mathrm{HMZ}$ versus WT DEGs were plotted against DEGs of normal C57BL/6 livers versus murine hepatoma cell line Hepa1-6 (Figure 1H). As anticipated, genes upregulated in the WT liver were preferentially 
expressed at higher levels in normal liver compared to liver cancer (565 versus 69, respectively). In contrast, genes more highly expressed in $\alpha 7 \mathrm{HMZ}$ livers were not enriched in liver cancer (Figure $1 \mathrm{H}$ and S1D). Taken together, these results indicate that $\mathrm{P} 2-\mathrm{HNF} 4 \alpha$ drives a specific program of gene expression in the adult liver distinct from that of $\mathrm{P} 1-\mathrm{HNF} 4 \alpha$ that is neither completely fetal- nor cancer-like, suggesting an alternative role for P2-HNF4 $\alpha$.

\section{P2-HNF4a livers are less sensitive to the circadian clock}

Since NRs are known to play an important role in regulating the circadian clock in the liver (Tahara and Shibata, 2016; Zhao et al., 2014), RNA-seq of WT and $\alpha 7 \mathrm{HMZ}$ livers was performed at three different time points (10:30, 13:30, 20:30, equivalent to zeitgeber time (ZT) $3.5,6.5$ and 13.5 , respectively). While the expression of $\sim 250$ to 500 genes was significantly altered (padj $<0.01$, absolute $\log 2 \mathrm{FC} \geq 1$ ) between any two of the time points in WT mice, less than half that number was altered in $\alpha 7 \mathrm{HMZ}$ livers (Figure 2A, top), suggesting a reduced sensitivity of $\alpha 7 \mathrm{HMZ}$ livers to the circadian clock. There were also more genes down- than upregulated in $\alpha 7 \mathrm{HMZ}$ livers (Figure 2A, bottom), consistent with the loss of AF-1 function in vitro (Nakhei et al., 1998; Torres-Padilla et al., 2002). A volcano plot of $\alpha 7 \mathrm{HMZ}$ DEGs also shows a greater number of genes increased in WT compared to $\alpha 7 \mathrm{HMZ}$ livers at 10:30 AM (ZT 3.5), including several cytochrome P450 (Cyp) genes and the NR gene CAR (Nrli3) (Figure 2B).

To examine the impact of P2-HNF4 $\alpha$ on other NR genes, we compared the FPKM values of all NR genes across all three time points. HNF4 $\alpha$ was the most highly expressed NR in both WT and $\alpha 7 \mathrm{HMZ}$; the next most abundant NR, Rxra, was expressed at roughly $25 \%$ the level of Hnf4a (Figure S2A). While most NRs displayed similar circadian oscillations in WT and 
$\alpha 7 \mathrm{HMZ}$ livers, there were some notable exceptions: CAR (Nrli3) was highly downregulated in $\alpha 7 \mathrm{HMZ}$ at all three time points (Figure S2A, arrow). Rev-Erb $\beta$ (Nr1d2), ROR $\gamma$ (Rorc) and PPAR $\alpha$ (Ppara), all involved in the transcriptional feedback loop that drives circadian expression in the liver (Tahara and Shibata, 2016), exhibited significantly reduced expression in $\alpha 7 \mathrm{HMZ}$ livers at one time point (Figures S2B), again suggesting a decreased responsiveness to the clock.

\section{HNF4a is one of the most highly expressed TFs in the liver}

Consistent with the relative abundance of $\mathrm{HNF} 4 \alpha$ protein in the adult liver (Bolotin et al., 2011; Sladek et al., 1990), HNF4 $\alpha$ had one of the highest transcript levels of any TF, higher even than subunits of RNA polymerase II (e.g., Polr2m, Polr2b) (Figure 2C). The other liver-enriched TFs (LETFs, Cebpa, Onecut2, Foxa1, Hnfla, HNF1b) had transcript levels at least 10-fold lower than Hnf4a (Figure 2C, inset, arrows), consistent with HNF4 $\alpha$ being a major regulator of liverspecific gene expression. Several TFs showed statistically significant differences between WT and $\alpha 7 \mathrm{HMZ}$ (Figure $2 \mathrm{C}$, asterisk), including those known to play a role in sexual dimorphic gene expression (Stat5a, Stat5b, Ahr, NrOb2) (Figure S2D and S2B) (Oshida et al., 2016; Clodfelter et al., 2007). Interestingly, Esrl (estrogen receptor alpha, ER $\alpha$ ) expression was modestly upregulated in $\alpha 7 \mathrm{HMZ}$ while $\mathrm{Ar}$ (androgen receptor, AR) was notably downregulated (Figure $2 \mathrm{E})$, suggesting a potential "feminization" of the $\alpha 7 \mathrm{HMZ}$ liver.

\section{P2-HNF4a dysregulates the expression of genes involved in fatty acid, steroid and xenobiotic/drug metabolism}

HNF4 $\alpha$ is a known regulator of Phase I and Phase II enzymes (Hwang-Verslues and Sladek, 2010) and has been computationally linked to sexually dimorphic and circadian 
expression of those genes (Hirao et al., 2011). Therefore, we examined the level of expression of all cytochrome P450 (Cyp) genes (Phase I) as well as glutathione S-transferases (Gst) and UDP glucuronosyltransferases (Ugt) (Phase II). While the diurnal pattern of expression was generally the same in WT and $\alpha 7 \mathrm{HMZ}$, the absolute level of expression was often altered (Figure 3A). For example, the expression of Cyp2c50 and Cyp2c54, which encode enzymes that metabolize linoleic acid, the endogenous HNF4 $\alpha$ ligand (Yuan et al., 2009), was much lower in $\alpha 7 \mathrm{HMZ}$ livers (Figures 3A and 1E). Several Ugt genes were dysregulated and metabolomic analysis revealed a significant (padj $<0.01$ ) decrease in UDP glucuronic acid in $\alpha 7 \mathrm{HMZ}$ livers (Figure 3A, bottom). Since glucose is needed to make UDP glucuronic acid, this decrease could be linked to carbohydrate metabolism (see Figure 7).

The NR CAR (Nrli3) is downregulated 10- to 18-fold in $\alpha 7 \mathrm{HMZ}$ mice (Figure 3B), as reported previously (Briançon and Weiss, 2006), and could explain some of the changes in Cyp gene expression observed in $\alpha 7 \mathrm{HMZ}$ livers (Tolson and Wang, 2010). In contrast, the expression of PXR (Nrli2), which is known to co-regulate many Phase I and II genes with CAR and to be upregulated by HNF4 $\alpha$ in fetal liver (Kamiya et al., 2003; Tolson and Wang, 2010), was not altered (Figure S2C), suggesting that the primary role of P2-HNF4 $\alpha$ in the adult liver may not be to regulate xenobiotic metabolism.

In addition to $C y p 2 c 50 / 54$, transcript levels of other fatty acid metabolic enzymes were also decreased in $\alpha 7 \mathrm{HMZ}$ livers. Cyp2b10 and Ephx2 (Figure 3C), which convert arachidonic acid to oxylipins via a two-step process (Wagner et al., 2011), were significantly downregulated, as were all four DiHETrE products of arachidonic acid in the CYP2B10-EPHX2 pathway (Figure 3D), confirming a phenotypic effect on fatty acid metabolism. Changes in gene expression in the steroid metabolism pathway were also observed in $\alpha 7 \mathrm{HMZ}$ livers with an 
increase in Cyp17al and a decrease in Srd5al and Hsd3b5 (Figure 3E). CYP17A1 plays a predominant role in steroid hormone biosynthesis, while steroid 5-alpha-reductase (Srd5al) metabolizes the conversion of testosterone into the more potent dihydrotestosterone (DHT) and 3 beta-hydroxysteroid dehydrogenase type $5(\mathrm{Hsd} 3 \mathrm{b5})$ is typically lower in female livers (Conforto and Waxman, 2012). Tellingly, several of the most significantly increased transcripts in $\alpha 7 \mathrm{HMZ}$ livers, including Cyp2b9, Cyp2b13 and Cyp2a4 (Figure 3F), are female-specific, have testosterone hydroxylase activity and are known to be regulated by HNF4 $\alpha$ (Wiwi et al., 2004). Furthermore, Ephx2 expression and activity is downregulated by estrogen (Huang and Sun, 2018), which could explain the observed decrease in DiHETrEs in $\alpha 7$ HMZ livers. All told, these results are consistent with the "feminization" of the $\alpha 7 \mathrm{HMZ}$ livers suggested by the increase in ER $\alpha$ and decrease in AR expression (Figure 2E).

\section{P1- and P2-HNF4a isoforms have similar but non-identical DNA binding profiles both in vivo and in vitro}

To determine whether the $\mathrm{P} 2-\mathrm{HNF} 4 \alpha$ transcriptional program is due to alterations in chromatin binding, ChIP-seq analysis was performed at 10:30 AM (ZT3.5) using an antibody $(\alpha 445)$ that recognizes both isoforms (Figure 1A). Consistent with the high level of expression of the Hnf4a gene, there was a large number of HNF4 $\alpha$ binding events in both WT and $\alpha 7 \mathrm{HMZ}$ livers ( 40,000 peaks). While the vast majority of peaks were similar in the two sets of mice, $\sim 1.4$ to $2.6 \%$ of the peaks were enriched for a particular isoform (WT unique: 572 peaks; $\alpha 7 \mathrm{HMZ}$ unique: 1067 peaks) (Figure 4A). Analysis of the feature distribution of the ChIP peaks shows that both WT- and $\alpha 7 \mathrm{HMZ}$-unique peaks were less frequently located in the promoter 
region $(\leq 2 \mathrm{~kb}$ from +1$)$ than the common peaks and the $\alpha 7 \mathrm{HMZ}$-unique peaks were enriched in intronic regions (Figure 4B).

Motif mining showed that the most common motif in both the WT and $\alpha 7 \mathrm{HMZ}$ unique peaks was an HNF4 $\alpha$ motif (xxxxCAAAGTCCA). To determine whether there might be additional TFs bound in those peaks, we analyzed the DNA sequence of the uniquely bound peaks with an HNF4 $\alpha$-trained support vector machine (SVM) algorithm and categorized the peaks into one of four categories $(>2,2$ to $1.75,1.75$ to 1.5 and 1.5 to $1.25 \mathrm{SVM}$ score) based on the single highest-scoring SVM motif within the peak. All but a few peaks fell into one of these categories suggesting that the isoform-specific peaks are likely due to direct binding to the DNA. Nonetheless, de novo motif calling with MEME-ChIP revealed different TF motifs in some of the isoform-specific peaks. CEBPA and FOX were the only motifs significantly enriched in WTunique peaks, but several motifs were found in a7HMZ-unique peaks, including SOX, GATA5, SMAD2, ETS, CEBPB, FOX and PAR bZIP (Figure 4C).

To investigate the innate DNA binding specificity of the HNF4 $\alpha$ isoforms, we designed PBMs with variations on HNF4 $\alpha$ consensus motifs (a direct repeat with a spacing of 1, DR1, AGGTCAxAGGTCA, or DR2, AGGTCAxxAGGTCA), as well as genomic sequences mined from HNF4 $\alpha$ ChIP-seq peaks (Figure 4D, top middle). In total, 44,000 test sequences were spotted in quadruplicate on a glass slide and probed with human HNF4 $\alpha 2$ or HNF4 $\alpha 8$ ectopically expressed in COS-7 cells or with liver nuclear extracts (NEs) from WT and $\alpha 7 \mathrm{HMZ}$ mice (HNF4 $\alpha 2 / \alpha 8$ have a 10-amino acid insertion in the F domain of HNF4 $\alpha 1 / \alpha 7$, respectively.) Scatter plot analysis of the PBM scores verified that the two HNF4 $\alpha$ isoforms exhibited nearly identical DNA binding affinity and specificity across all test sequences in the COS-7 extracts (Figure 4D, top left). Liver NEs from WT and $\alpha 7 \mathrm{HMZ}$ mice were also nearly identical except for 
a subset of sequences that differed between WT and $\alpha 7 \mathrm{HMZ}$ (Figure 4D, top right). Motif analysis of the two groups of sequences, shown in green and red, revealed a preference for HNF4 $\alpha$ in WT livers for GC-rich sequences recognized by SP1/KLF proteins (Figure 4D, bottom right, middle). A similar, albeit less pronounced, preference was noted in the COS-7 extracts (Figure 4D, bottom left). Consistently, HNF4a1 has been found to interact with SP1 both on and off chromatin, an interaction that involves the N-terminal domain of HNF4 $\alpha 1$ (Hwang-Verslues and Sladek, 2008; Kardassis et al., 2002; Takahashi et al., 2002).

\section{HNF4a isoforms have unique interactomes}

To assess the contribution of differential chromatin binding to changes in gene expression, we cross-referenced the ChIP-seq and RNA-seq datasets at the 10:30 AM time point and found that $22 \%$ of WT-specific (62 out of 294) and $27 \mathrm{HMZ}$-specific genes (41 out of 181) have one or more unique ChIP peaks within $50 \mathrm{~kb}$ of the transcription start site (TSS, +1) (Figure 5A). WT-specific genes matching these criteria include Nr1i3, Cyp2c50, Cyp2c54, Rarres1, Fmn1, Cdhr5, and Camk1d, while a7HMZ-specific genes include Cyp2b9, Fgfrl, Wnk4, Cyp4a14, Ppl, Vnn1, Acot1, and Cyp17a1 (Table S2E and S2F). Many of the most dysregulated genes contained differentially bound peaks within $\sim 5 \mathrm{~kb}$ of +1 -- Nr1i3 (CAR), Apoa4, Cyp2c50, Cyp2c54, Cyp2b9, Cyp4a14, Acot1, Cyp17a1,Ucp2, Cyp2d26 and Treh (Figures 5B, 5C and S4AB). While the differential peaks were typically not the only nor the largest peak in the gene, they could reflect rapid cycling on and off the DNA with functional consequences.

Since the majority of dysregulated genes had no nearby HNF4 $\alpha$ isoform-specific ChIP peak, we examined HNF4 $\alpha$ protein-protein interactions in WT and $\alpha 7 \mathrm{HMZ}$ livers by RIME at 10:30 (ZT3.5) and 20:30 (ZT13.5). Both time points yielded a considerable number of 
interacting proteins at least eight-fold above the background, including many proteins that bound a single isoform (10:30: $167 \mathrm{WT}$-specific, 108 a7HMZ-specific; 20:30: 357 WT-specific, 256 a7HMZ-specific) (Figure 5D, top). There was considerable overlap between the common groups for the two time points ( 96 proteins bound HNF4 $\alpha$ in both WT and $\alpha 7 \mathrm{HMZ}$ livers at both time points), underscoring the robustness of the method. There were also many proteins that bound both isoforms but only at a single time point (10:30: 141; 20:30: 401). Notably, core circadian regulator CRY1 bound HNF4 $\alpha$ in both WT and $\alpha 7 \mathrm{HMZ}$ livers but only at 10:30 AM (Figure 5D, bottom). In contrast, BHLHE40 bound both isoforms at both 10:30 and 20:30, while NFIL3 uniquely bound in WT livers and ARNTL (BMAL1) and CLOCK in $\alpha 7 \mathrm{HMZ}$ but only at 10:30 (Figure 5D, bottom). These findings are consistent with recent reports of HNF4 $\alpha$ interacting with the clock machinery and playing a role in maintaining circadian oscillations in the liver (Qu et al., 2018).

Several LETFs interacted with both isoforms but only at one time point (10:30 only: CEBPA, CEBPB, HNF1B, ONECUT2; 20:30 only: FOXO1, ONECUT1); only HNF1A interacted at both time points (Figure 5D, bottom, middle). Many NRs interacted with HNF4 $\alpha$ in both WT and $\alpha 7 \mathrm{HMZ}$ livers, including NR3C1(GR) and NR0B2 (SHP), both of which have been shown previously to functionally interact with $\mathrm{HNF} 4 \alpha$, further validating the RIME results (Hall et al., 1995; Lee et al., 2000). There were also isoform-specific interactions, mostly with WT at 10:30 (NR1H2, NR2C1, NR2C2, PPARA). Interestingly, xenobiotic receptor PXR (NR1I2) interacted with HNF4 $\alpha$ but only in $\alpha 7 \mathrm{HMZ}$ livers at 10:30 (Figure 5D, bottom left and right). While the expression of Nrli2 was not changed in a7HMZ livers (Figure S2C), an environmental estrogen that activates PXR has been shown to increase the expression of two female-specific Cyp genes (Cyp2b9 and Cyp2a4) in male mice: both are highly upregulated in a7HMZ livers and 
bound by HNF4 $\alpha$ (Figure 5C and Table S2E) (Hernandez et al., 2006). HNF4 $\alpha$ in $\alpha 7 \mathrm{HMZ}$ livers also uniquely interacted with ESRRG (ERR $\gamma, N r 3 b 3)$ but only at 20:30: ERRs play important roles in mitochondrial biogenesis and function, including fatty acid oxidation (Hock and Kralli, 2009). Interestingly, ERR DNA binding motifs were found in $\alpha 7 \mathrm{HMZ}$ ChIP peaks but not WT (Figure S3B).

There were many other TFs and co-regulators that interacted with a single HNF4 $\alpha$ isoform, often in a circadian fashion (Figure 5D, bottom), which could explain the observed differential gene expression between WT and $\alpha 7 \mathrm{HMZ}$. Several of these proteins were previously confirmed by more conventional means (Maeda et al., 2002; Ruse et al., 2002; Sladek et al., 1999; Torres-Padilla et al., 2002). Finally, there were several signaling molecules that interacted uniquely with the isoforms and at distinct time points -- one or more of these could also contribute to isoform-specific gene expression, independent of ChIP peaks (Figure S4D).

\section{HNF4a isoforms differentially impact circadian gene expression}

Interactions with circadian TFs suggest that HNF4 $\alpha$ may play a role in the hepatic clock. Analysis of all DEGs between any two time points $(10: 30,13: 30$ or $20: 30$; padj $<0.01$ and $\log 2 \mathrm{FC}>2$ ) for either WT or $\alpha 7 \mathrm{HMZ}$ yielded 53 genes, including commonly known circadian genes (Cry1, Rorc, Dbp, Bhlhe41, Usp2, Per2, Per3, Arntl, and Nr1d1) as well as many metabolism-related genes (Fmo3, Lpl, Car3, Corin, Npas2, Hmgcs1, Mme, Slc45a3, Hsd3b4, $H s d 3 b 5$, Slc10a2) (Figure 6A top). While most of these circadian-regulated genes showed the same general profile in WT and $\alpha 7 \mathrm{HMZ}$ livers, there were some differences in the magnitude of the circadian effect between the genotypes. For example, Fmo3, a drug metabolizing gene whose expression varies greatly between individuals, had a much higher expression in $\alpha 7 \mathrm{HMZ}$ livers at 
20:30. In contrast, Aqp8, a water channel protein important for mitochondrial respiratory function (Ikaga et al., 2015), had much lower levels of expression in $\alpha 7 \mathrm{HMZ}$ at all time points (Figure 6A, arrows).

While the majority of the clock machinery maintained cyclic expression in both genotypes (Figure 6A bottom), there were significant differences in expression between WT and a7HMZ in core clock components Arntl, Clock, Cry1, Nfil3, Npas2 and Per3 at one or more time points (Figure 6B), as well as Rorc and Ppara (Figure S2B). The fact that other core components of the clock machinery did not show differences between the two genotypes (e.g., Per1, Per2, Rora, Bhlhe40) (Figure S5A) suggests that the effect of P2-HNF4 $\alpha$ on the clock is a specific one.

A sample distance matrix further confirmed a subtle yet real effect of P2-HNF4 $\alpha$ on the hepatic clock. While the WT replicates at a given time point are much more similar to each other than they are to other time points, $\alpha 7 \mathrm{HMZ}$ replicates show strong self-identity only in the 13:30 samples (Figure 6C). This is despite the fact that a principal component analysis (PCA) showed a good separation and categorization of each sample group (Figure S7A).

\section{P2-HNF4 $\alpha$ is expressed at discrete times in the normal adult liver}

While expression of P2-HNF4 $\alpha$ protein in the normal adult liver has not been previously reported, this could be due to the time of day that livers are typically harvested (before midday). Since the current results show links between P2-HNF4 $\alpha$ in $\alpha 7 \mathrm{HMZ}$ livers and the circadian clock, we harvested livers from WT mice at four time points (ZT3, ZT9, ZT15, ZT21) and looked for P2-HNF4 $\alpha$ mRNA by qPCR and protein by immunoblot (IB). The results show expression of P2-HNF4 $\alpha$ at ZT9 (4 pm) and ZT21 (4 AM) and a further increase in Clock KO 
livers. In contrast, P1-HNF4 $\alpha$ did not show a significant circadian effect in either WT or CLOCK KO mice (Figures 6D, 6E, S5B, S5C).

\section{Metabolomic profiling indicates a role for P2-HNF4a in ketogenesis}

Since metabolism is tightly linked to the clock in the liver (Eckel-Mahan et al., 2012, 2013; Ribas-Latre and Eckel-Mahan, 2016), we performed metabolomic analysis of primary metabolites and complex lipids on WT and $\alpha 7 \mathrm{HMZ}$ livers at 10:30. Approximately one-quarter of the primary metabolites $(100$ out of 359 total) were significantly down-regulated $(p<0.05)$ in a7HMZ livers (Figure 7A, up in WT). Metabolite Set Enrichment Analysis showed that the top four enriched categories in WT are involved in carbohydrate metabolism and protein biosynthesis (Figure S6A). Glucose and pyruvate were both significantly down in $\alpha 7 \mathrm{HMZ}$ livers (Figure 7B), as was PEPCK (Pckl), an important enzyme in gluconeogenesis (Figure S6B). Genes in pathways downstream of pyruvate were also significantly decreased in $\alpha 7 \mathrm{HMZ}$, including lactate dehydrogenase $(L d h a, L d h d)$, pyruvate carboxylase $(P c x)$ and citrate synthase $(C s)$ in the Kreb's cycle (Figure S6C), as was citric acid, a key intermediate in the cycle (Figure 7B). Kreb's intermediates oxalic and succinic acid were also reduced although they did not reach significance (Figure S6D). In contrast, genes involved in the formation of ketone bodies were upregulated in $\alpha 7 \mathrm{HMZ}$ (Hmgcs2, Hmgcl) (Figure S6E), as was the ketone body $\beta$ hydroxybutyric acid (Figure 7B), as previously reported (Briançon and Weiss, 2006). Levels of hundreds of complex lipids were altered (up or down) in $\alpha 7 \mathrm{HMZ}$ livers, including a notable increase in total triglycerides, diacylglycerides and acylcarnitines in the $\alpha 7 \mathrm{HMZ}$ liver and a decrease in phospholipid species (Figures 7AC and S6F). 
Since ketone bodies are elevated upon fasting, we performed RNA-seq on livers from 12hr fasted WT and $\alpha 7 \mathrm{HMZ}$ mice. The transcriptomes for both WT and $\alpha 7 \mathrm{HMZ}$ fasted livers were quite distinct from the fed time points as well as from each other (Figures S7A and S7B): WT mice had more genes altered upon fasting (673 versus 531 in $\alpha 7 \mathrm{HMZ}$ ) as well as more WTspecific genes either up- or downregulated (Figure 7D). Liver-to-body weight ratios were significantly lower in $\alpha 7 \mathrm{HMZ}$ versus WT fed mice; in contrast, in fasted livers the ratio was lower in WT (Figure 7E). Since WT mammals are known to store fat in their liver during periods of fasting and since fasted $\alpha 7 \mathrm{HMZ}$ livers accumulate more fat than WT mice (Figure 7C)(Briançon and Weiss, 2006), these results suggested that P2-HNF4 $\alpha$ might promote a "fasting-response" program, consistent with the expression of P2-HNF4 $\alpha$ at ZT9, near the end of the daily fasting period.

When the mice were subjected to a prolonged fast, unexpectedly, $50 \%$ of the $\alpha 7 \mathrm{HMZ}$ mice died after $\sim 60 \mathrm{hrs}$; in contrast, $\alpha 1 \mathrm{HMZ}$ and WT mice survived a full $72 \mathrm{hrs}$ without food (Figure 7F). Mortality was not due to hypoglycemia as blood glucose levels did not drop below $65 \mathrm{mg} / \mathrm{dL}$; in fact, they increased after $48 \mathrm{hrs}$ of fasting at ZT11, especially in $\alpha 1 \mathrm{HMZ}$ (Figure S7C). In contrast, circulating ketone bodies were highly elevated in the $\alpha 7 \mathrm{HMZ}$ mice that survived the $60-\mathrm{hr}$ fast $(4.25 \mathrm{mM})$ (Figure $7 \mathrm{G})$, and suggested that the a7HMZ mice undergoing a prolonged fast died of ketoacidosis.

Since the $\alpha 7 \mathrm{HMZ}$ transcriptome showed signs of "feminization" and since females tend to have higher levels of ketone bodies than males (Halkes et al., 2003; Marinou et al., 2011), we examined whether the elevated levels of ketone bodies in WT females is due to the ability to express P2-HNF4 $\alpha$. As anticipated, in WT mice ketone bodies were higher near the end of the daily fast (ZT11, 7 PM) than at the end of the feeding period (ZT23, 7 AM), in both males and 
females (Figure 7G). In contrast, $\alpha 7 \mathrm{HMZ}$ males had ketone bodies at ZT23 nearly as high as at ZT11. Importantly, $\alpha 7 \mathrm{HMZ}$ and WT females had much higher levels of ketone bodies at ZT11 than their male counterparts, whereas the $\alpha 1 \mathrm{HMZ}$ females had levels similar to $\alpha 1 \mathrm{HMZ}$ males and much lower than either WT or $\alpha 7 \mathrm{HMZ}$ females (Figures $7 \mathrm{G}$ ). This suggests that P2-HNF4 $\alpha$ is required for the elevated levels of ketone bodies in females.

\section{Discussion}

While many mammalian genes have multiple promoters that drive expression of proteins with alternative N-termini, the physiological relevance of those different isoforms is seldom known. Using exon-swap mice and omics approaches, we show for the first time that the alternative isoform of the $H n f 4 a$ gene (P2-HNF4 $\alpha$ ), previously thought to be expressed only in fetal liver and liver cancer, plays an important metabolic role in the adult liver and is implicated in both the circadian clock and sex-specific gene expression.

\section{Both P1- and P2-HNF4a are required for metabolic homeostasis in males and females}

The "P2-HNF4 $\alpha$ program" is characterized by a decrease in carbohydrate metabolism and an increase in hepatic fat storage and utilization, as well as ketogenesis, which typically occur during periods of fasting (Puchalska and Crawford, 2017). Altered expression of genes involved in fatty acid oxidation or oxidative phosphorylation in the mitochondria are consistent with a shift from carbohydrates to fatty acids as an energy source (e.g., Hmgcs2, Acot1, Ucp2, Figure $1 \mathrm{~F}$ and Table S2G). In contrast, P1-HNF4 $\alpha$ drives gluconeogenesis and is required to temper the P2-HNF4 $\alpha$ response to avoid ketoacidosis. Only WT mice, which express both HNF4 $\alpha$ isoforms in the liver, achieve homeostatic balance between carbohydrate and lipid metabolism (Figure 
7H). This balance is achieved on a daily basis by upregulating P2-HNF4 $\alpha$ at the end of the fasting period ( ZT9) (Figure 6), resulting in the well characterized elevation of ketone bodies right before feeding (Chavan et al., 2016). Intriguingly, P2-HNF4 $\alpha$ is also required for the elevated levels of ketone bodies in female mice (Figure 7G), consistent with a "feminization" of the $\alpha 7 \mathrm{HMZ}$ livers and previous results showing that $\mathrm{KO}$ of $\mathrm{HNF} 4 \alpha$ in the adult liver leads to a loss of male-specific genes and an increase of female-specific genes (Holloway et al., 2008). Finally, P2- but not P1-HNF4 $\alpha$ interacts with the NAD-dependent deacetylase SIRT1, which is activated upon fasting and is associated with fatty acid oxidation, ketogenesis and fatty liver (Figure 5D) (Nassir and Ibdah, 2016).

\section{Multiple mechanisms are responsible for HNF4a isoform-specific gene regulation}

Our results indicate that $\mathrm{P} 2-\mathrm{HNF} 4 \alpha$ drives its unique transcriptional program via multiple mechanisms. Differential recruitment of co-regulators to target gene promoters could explain altered expression of genes such as Ces2e, which encodes carboxylesterase 2, an enzyme that hydrolyzes triacylglycerols (Figure 7I top and Figure 5D). Both P1- and P2-HNF4 $\alpha$ bind the Ces $2 e$ promoter in a similar fashion but Ces $2 e$ is expressed at much higher levels in $\alpha 7 \mathrm{HMZ}$ livers compared to WT, which could explain the elevated levels of triglycerides in $\alpha 7 \mathrm{HMZ}$ livers (Figures 1E, S4C, 7C). A second potential mechanism is differential binding to regulatory regions (Figure 7I bottom). An enriched ChIP-seq peak in a7HMZ livers, for example, could explain the upregulation of a key enzyme in $\beta$-oxidation of fatty acids, Acot1 (Figures 7I middle and S4A). A third mechanism involves differential recruitment and/or interaction of TFs with a given HNF4 $\alpha$ isoform (Figure 7I bottom). For example, PPAR $\alpha$ is known to be a major player in ketogenesis, activating the expression of the mitochondrial enzyme HMGCS2 which catalyzes 
the first step in ketogenesis (Puchalska and Crawford, 2017). P1-HNF4 $\alpha$ has been shown to decrease Hmgcs2 expression by repressing PPAR $\alpha$-dependent activation (Rodríguez et al., 1998). This repression could be facilitated by a unique protein-protein interaction between P1HNF4 $\alpha$ and PPAR $\alpha$ (Figure 5D). In contrast, in $\alpha 7 \mathrm{HMZ}$ livers Hmgcs 2 expression is elevated even though PPAR $\alpha$ expression is somewhat reduced and HNF4 $\alpha$ ChIP-seq peaks in $\alpha 7 \mathrm{HMZ}$ livers are similar to those in WT (Figures S2B, S4C, S6E). Similarly, specific interactions between P2-HNF4 $\alpha$ and TFs involved in sex-specific gene expression (e.g., NR1I2, SP1 family/KLF) could contribute to increased expression of female-specific genes such as Cyp $2 b 13$ (Figures 3F, 5D, S4C) (Hernandez et al., 2006). Additional mechanisms driving the P2-HNF4 $\alpha$ program include differential interaction with signaling molecules, altered expression of other TFs, such as those that play a role in sex-specific gene expression (Stat5b, Stat5a, estrogen and androgen receptors) (Hirao et al., 2011; Oshida et al., 2016), and elevated levels of ketone bodies which can impact histone deacetylase activity, as well as the circadian clock (Tognini et al., 2017) (Figures 2, S4D, 7G).

\section{Physiological and pathological triggers of the P2-HNF4a program}

There are now three known physiological conditions in which P2-HNF4 $\alpha$ is expressed in the liver -- fetal liver and ZT9 and ZT21 in adult liver (Figure 6). Increased expression of P2HNF4 $\alpha$ expression right before birth (E17.5), followed by a sharp decline after birth (Briançon et al., 2004; Torres-Padilla et al., 2001), could explain why the $\alpha 7 \mathrm{HMZ}$ transcriptome is not more similar to that of the E14.5 fetal liver: rather than promoting early liver development, the role of P2-HNF4 $\alpha$ appears to be a metabolic one, perhaps preparing the fetus to survive the birthing process and immediate postnatal period by increasing fat in the liver. The subsequent decrease in 
P2-HNF4 $\alpha$ expression after birth could be mediated by GR which is induced by stress hormones released during labor (Rando et al., 2016): GR preferentially increases the expression of P1HNF4 $\alpha$ (Bailly et al., 2009; Nakhei et al., 1998) which would in turn repress the P2 promoter (Briançon et al., 2004).

Factors responsible for increased expression of P2-HNF4 $\alpha$ at ZT9 have not been identified, but its expression seems to be required for the increased the level of ketogenic genes and ketone bodies in response to the daily fast (Figures S6E and 7BG). The role of P2-HNF4 $\alpha$ at ZT21 is more difficult to explain as ketone bodies are low at that time (Figure 7G) (Chavan et al., 2016). Total protein synthesis is increased at $~ Z T 22$ (Robles et al., 2014), as well as both P2and P1-HNF4 $\alpha$-specific targets (Figure S7D), so expression of P2- (and P1-)HNF4 $\alpha$ at ZT21 might be the result of a global effect on protein synthesis.

In addition to physiological triggers, there are now four pathological conditions in which P2-HNF4 $\alpha$ is known to be elevated in the adult liver -- cancer (Tanaka et al., 2006), high fat diet (Fekry et al., 2018), disrupted clock (Figure 6DE) and alcoholic hepatitis (Argemi et al., 2019). In terms of cancer, our results indicate that $\mathrm{P} 2-\mathrm{HNF} 4 \alpha$ is not oncogenic per se -- the P2-HNF4 $\alpha$ transcriptome shows only a partial overlap with HCC, key proliferation markers (Ki67 and PCNA) are not upregulated in $\alpha 7 \mathrm{HMZ}$ livers, there is no evidence of hepatomegaly (Figures $1 \mathrm{H}$, S1DE, 7E) and no increase in spontaneous, macroscopic tumors have been observed in $\alpha 7 \mathrm{HMZ}$ livers, even in older mice (unpublished observation). While HCC patients with increased P2$\mathrm{HNF} 4 \alpha$ have a poor prognosis (Cai et al., 2017), rather than acting as an oncogene per se, P2HNF4 $\alpha$ may be upregulated simply due to a decrease in the expression of the tumor suppressor P1-HNF4a (Bailly et al., 2009; Nakhei et al., 1998) and inadvertently promote liver cancer progression via metabolic effects. For example, acylcarnitines are elevated in $\alpha 7 \mathrm{HMZ}$ livers 
(Figures 7C, S6F) and have been identified as potential diagnostic and prognostic biomarkers for HCC (Lu et al., 2016; Yaligar et al., 2016). Several matrix metalloproteinases (Mmp14, Mmp15, Mmp19), which are linked to poor prognosis of liver or colorectal cancer patients (Chen et al., 2011, 2019; Zheng et al., 2019), are also upregulated by P2-HNF4a (Table S1). Finally, dysregulation of genes involved in drug metabolism could also impact treatment of liver cancer (Figure 3).

The second condition that leads to expression of P2-HNF4 $\alpha$ in the adult liver -- high fat diet -- could be related to both cancer and the third condition, disrupted clock. We recently reported that P2-HNF4 $\alpha$ expression is increased in the livers of mice fed a high fat diet and that the circadian regulator BMAL1 represses P2-HNF4 $\alpha$ expression in HCC (Fekry et al., 2018). Consistently, P2- but not P1-HNF4 $\alpha$ interacts with BMAL1 (ARNTL) and CLOCK and the Clock KO increases P2- but not P1-HNF4 $\alpha$ expression (Figures 5D and 6DE). Dysregulation of the clock, such as during jet lag, could potentially contribute to liver cancer by upregulating P2HNF4 $\alpha$ (Figure 6DE) (Kettner et al., 2016).

The fourth pathological condition where P2-HNF4 $\alpha$ is expressed in the liver -- human alcoholic steatohepatitis (Argemi et al., 2019) -- is consistent with increased fat in $\alpha 7 \mathrm{HMZ}$ livers and an enrichment of genes associated with alcoholism in $\alpha 7 \mathrm{HMZ}$ mice (Figures 1F, 7C). The TGF $\beta$ pathway is implicated in P2-HNF4 $\alpha$ expression under this scenario; SMAD binding motifs were found in $\alpha 7 \mathrm{HMZ}$ ChIP-seq peaks but not WT peaks (Figure S3B).

In summary, our results with the exon swap mice reveal important functional differences between the HNF4 $\alpha$ isoforms and suggest a new role for P2-HNF4 $\alpha$ in the liver. Future studies are required to identify conditions that cause the switch between the isoforms in a wildtype liver and to further explore the impact of that switch on liver physiology and disease. 


\section{Materials \& Methods}

(see Supplemental Methods for additional methods and details)

\section{Animal models}

Young adult (16 to 20 weeks) male WT and $\alpha 7 \mathrm{HMZ}$ mice in a mixed 129/Sv plus C57BL/6 background (Briançon and Weiss, 2006) were fed a standard lab chow (LabDiet, \#5001, St. Louis, MO) and used for RNA-seq, CHIP-seq, RIME analysis (all samples from the same set of mice), and oxylipin analysis. The $\alpha 7 \mathrm{HMZ}$ male mice used for primary metabolite and complex lipid metabolomic analysis were backcrossed to C57BL/6N for $10+$ generations and used with C57BL/6N WT controls ( $\mathrm{n}=8,35$ weeks of age). $\alpha 7 \mathrm{HMZ}$ and $\alpha 1 \mathrm{HMZ}$ (backcrossed 10+ generations into $\mathrm{C} 57 \mathrm{BL} / 6 \mathrm{~N}$ ) were compared to C57BL/6N (WT) controls for newborn liver analysis (mixed-sex) and glucose/ketone body analysis (males and females; $\sim 16$ to 20 weeks of age). Clock-deficient (Clock KO) male mice were provided by Dr. David Weaver (Debruyne et al., 2006). All mice were fed ad libitum and kept in 12-hr light/dark conditions, unless indicated otherwise, and euthanized by $\mathrm{CO}_{2}$ asphyxiation followed by tissue harvest at the indicated time points. Care and treatment of the animals were in strict accordance with guidelines from the Institutional Animal Care and Use Committee at the University of California, Riverside, or the McGovern Medical School, UT Health.

Expression profiling (RNA-seq) and analysis

Next generation sequencing of RNA (RNA-seq) was carried out as previously described (Vuong et al., 2015). WT and $\alpha 7 \mathrm{HMZ}$ male mice were sacrificed (n=3, aged 16-18 weeks) at the indicated time points -- 10:30, 13:30, 20:30 (ZT 3.5, ZT 6.5, and ZT 13.5, respectively) -- within a 30-min interval. Fasted mice had food removed from 22:30 (ZT15:30) to 10:30 AM (ZT3.5) 
the following day (12 hr). Libraries were submitted for 75-bp single-end sequencing with Illumina NextSeq 500 at the UCR IIGB Genomics Core. A total of 24 libraries ( 3 fed time points, 1 fasted time point, 2 genotypes each, 3 replicates) were multiplexed and sequenced in two separate runs, each of which yielded $\sim 600 \mathrm{M}$ reads, averaging $\sim 50 \mathrm{M}$ reads per sample.

Reads were aligned to the mouse reference genome (mm10) with TopHat v2.1.1 using default parameters except for allowing only 1 unique alignment for a given read. Raw read counts were calculated at the gene level for each sample using HTSeq v0.6.1. Library normalization was performed with EDASeq (Risso et al., 2011); within-lane normalization on GC content was performed with the LOESS method and between-lane normalization was performed with non-linear full quantile method. Normalization factors from EDASeq were used for differential expression analysis with DESeq2. Normalized read counts, FPKM (fragments per kilobase per million), and rlog (regularized $\log$ transformation) results were generated for downstream analysis.

\section{Chromatin Immunoprecipitation Sequencing (ChIP-seq) and SVM analysis}

ChIP-seq of isolated liver cells from WT and $\alpha 7 \mathrm{HMZ}$ males ( $\mathrm{n}=3$, aged 16-18 weeks) was performed as previously described (Vuong et al., 2015) using $4.2 \mu \mathrm{g}$ of affinity-purified antiHNF4 $\alpha(\alpha 445)$ (Sladek et al., 1990) or rabbit IgG control (Santa Cruz, cat\#sc-2027). Libraries were submitted for 50-bp single end sequencing by Illumina HiSEQ 2500 at the UCR IIGB Genomics core. Reads were aligned to the mouse reference genome (mm10) with Bowtie2. Peaks were called with MACS2 for individual samples, as well as a pooled peak dataset using the SPMR (signal per million reads) parameter. Aligned reads and MACS2 peak-sets were analyzed with DiffBind (Stark and Brown, 2011), with DESeq2 and library size equal to total aligned reads to identify common and uniquely bound regions of the genome. Default parameters 
were used unless noted otherwise. ChIP-seq peaks were called with MACS2 and then filtered on $-\log 10(p$-value $) \geq 10$, to approach six-fold enrichment above control. Differentially bound peaks were identified using DiffBind with MACS2 output. Curated peak lists were generated by filtering all results on peaks with "concentration" $\geq 5$; defined by DiffBind as the "mean $(\log )$ reads across all samples" in contrast. The kernel-based SVM was trained as previously described using results from independent HNF4 $\alpha$ PBM experiments (Bolotin et al., 2010).

\section{Protein Binding Microarrays (PBM)}

Protein binding microarrays (PBMs) were carried out as previously described (Bolotin et al., 2010). Nuclear extracts (NE) were prepared from COS-7 cells transiently transfected via $\mathrm{CaPO}_{4}$ with HNF4 $\alpha$ expression vectors for human HNF4 $\alpha 2$ (NM_00457) and HNF4 $\alpha 8$ (NM_175914) essentially as previously described (Jiang et al., 1995). Liver NE from WT and $\alpha 7 \mathrm{HMZ}$ mice were prepared as previously described (Yuan et al., 2009).A custom-designed array was ordered from Agilent (SurePrint G3 Custom GE 4x180k), which contained oligonucleotides $\sim 60$ nucleotides (nt) in length comprised of: sequences within 100 bp of the center of HNF4 $\alpha$ ChIP-seq peaks from proliferative Caco-2 cells (Verzi et al., 2010) were taken in 30-nt windows moving $5 \mathrm{nt}$ at each step; 17,250 permutations of canonical HNF4 $\alpha$ DR1 motifs (5'- AGGTCAAAGGTCA -3'); 500 permutations of DR2 motifs with variable spacer (5'AGGTCNNNNGGTCA -3'); 900 random control 13-mer DNA sequences. A total of $\sim 45,000$ test sequences were spotted in quadruplicate on the slide as single-stranded DNA. The DNA was made double-stranded and COS-7 or mouse liver NEs were applied. HNF4 $\alpha$ binding was imaged with 2- $\mu \mathrm{m}$ resolution using Agilent G2565CA Microarray Scanner at the UCLA DNA Microarray Core. Extraction and normalization of the data were as described previously (Bolotin et al., 2010). PWMs were generated using seqLogo. 
Rapid Immunoprecipitation and Mass Spectrometry of Endogenous Proteins (RIME)

RIME was performed as previously described (Mohammed et al., 2016) with slight modifications. Livers from the same mice used for the RNA-seq and CHIP-seq -- WT and $\alpha 7 \mathrm{HMZ}$ males $\mathrm{n}=3,16-18$ weeks of age sacrificed at 10:30 (ZT 3.5) or 20:30 (ZT13.5) -- were crosslinked and IP'd with the P1/P2 antibody. Multidimensional protein identification technology (MudPIT) analysis was performed by the UCR IIGB Proteomics Core. Raw MS1 and MS2 spectra were processed with Proteome Discoverer 2.1 (Thermo Scientific) and submitted to Mascot search engine to match against NCBI non-redundant mouse protein database. Only proteins with $1 \%$ FDR cut-off $(\mathrm{q} \leq 0.01)$ were considered for subsequent analysis. Area under the curve, as reported by Proteome Discoverer, was averaged together for WT and $\alpha 7 \mathrm{HMZ}$ samples $(n=3)$ at each time point. IgG samples $(n=3)$ from both WT and $\alpha 7 H M Z$ were averaged together to create a background sample. Areas were converted to $\log 2$ scale and the fold-change above IgG background was calculated for the WT and $\alpha 7 \mathrm{HMZ}$ samples. Proteins with less than 8-fold change above background were omitted. Similarly, a 8-fold difference between WT and $\alpha 7 \mathrm{HMZ}$ samples was used to identify unique protein interactions.

\section{Primary metabolite, complex lipids and oxylipin analysis}

All metabolomic analysis was performed at the West Coast Metabolomics Center at the University of California Davis as described previously (Deol et al., 2017) using liver tissue rinsed in cold PBS, snap frozen and stored in liquid nitrogen. Data (pmol/gm tissue or peak height) are presented as mean $+/$ - standard error of mean (SEM). Student's T-test was used to determine statistical significance $(\mathrm{p}<0.05)$ using GraphPad Prism v6. 
Primary metabolite and complex lipid analysis was on WT (C57BL/6N) and $\alpha 7 \mathrm{HMZ}$ (backcrossed into C67BL/6N) male mice harvested mid-morning and fed the standard chow ( $n=8$, aged 38 weeks). Fold-enrichment was performed using MetaboAnalyst (Xia and Wishart, 2002). One outlier from each group was removed before plotting and statistical analysis. Analysis of non-esterified oxylipins was performed on a mixed 129/Sv plus C57BL/6 background WT and $\alpha 7 \mathrm{HMZ}$ males (n=3 per group, aged 12-13 weeks). Tissue homogenates (100 mg) were extracted by solid phase extraction and analyzed by ultrahigh performance liquid chromatography tandem mass spectrometry (UPLC-MS/MS) (Agilent 1200SL-AB Sciex 4000 QTrap) as previously described (Matyash et al., 2008; Yang et al., 2009). Analyst software v.1.4.2 was used to quantify peaks according to corresponding standard curves with their corresponding internal standards.

\section{QUANTIFICATION AND STATISTICAL ANALYSIS}

Differential gene expression (DEG) was measured using raw read counts with DESeq2: statistical significance was defined as adjusted $p$-value $($ padj $) \leq 0.01$, unless otherwise noted. Legends denote thresholds using $\log 2$ fold change (log2FC) cutoffs. R library "gage" was utilized to identify differentially enriched KEGG pathways in Figure 1. Heatmaps were generated with pheatmap package in R; data were row-normalized before plotting, except for NR heatmap in Figure S2. Transcription Factor (TF) rankings for Cleveland plots were ordered at the 13:30 (peak HNF4 $\alpha$ expression) then manually curated with the aid of PANTHER (Mi et al. 2017). Venn diagrams were generated with VennDiagram package in R. Unique and common RIME results were submitted to DAVID for ontology analysis. Statistical significance for primary metabolite and complex lipid data defined as $\mathrm{p} \leq 0.05$ by Mann-Whitney U-test or Benjamini-Hochberg padj $<0.05$, as indicated. All barplots represent mean $\pm \mathrm{SEM}$; significant 
differences are noted between genotypes at a given time point, unless indicated otherwise. For FPKM plots, padj values are from DESeq2; in other plots, p-values are from two-way Student's T-test or One/Two-way ANOVA, as indicated. External expression datasets and analysis are described in Supplemental Methods.

\section{DATA AND SOFTWARE AVAILABILITY}

The raw and processed RNA-seq data have been deposited in GEO under GSE117972.

The raw and processed ChIP-seq data have been deposited in GEO under (in progress).

The processed PBM data have been deposited in the Nuclear Receptor DNA Binding Project (http://nrdbs.ucr.edu).

The raw metabolomics data (primary metabolites and complex lipids) have been deposited in Metabolomics Workbench (www.metabolomicsworkbench.com) under Project \#PR000461. 


\section{Acknowledgements}

We thank D Weaver for Clock KO mice, MC Weiss and N Briancon for HNF4 $\alpha$ exon swap mice and J Vizcaya for assistance with newborn livers. The work was supported by NIH R01DK094707, DK053895 and USDA National Institute of Food and Agriculture (Hatch project CA-R-NEU-5680) to FMS; NIEHS T32 Training Grant (5T32ES018827) and Crohn's and Colitis Foundation of America Career Development Award (\#454808) to PD; WCMC Pilot Project from NIH U24 DK097154 to FMS, in collaboration with OF; R01ES002710 and Superfund Research Program P42 EX004699 to BDH; Start-up funds from UT Health to KEM; NIH S10 OD010669 for the Orbitrap Fusion mass spectrometer.

\section{Author Contributions}

Conceptualization, J.R.D. and F.M.S.; Methodology, J.R.D., P.D., N.T., S.H.R., L.M.V., J.F., J.Y.; Software, J.R.D.; Validation, B.F., K.E-M.; Formal Analysis, J.R.D., P.D., J.F.;

Investigation, J.R.D., P.D., N.T., S.H.R., L.M.V., J.R.E., S.P., J.F., J.Y., B.F.; Data Curation, J.R.D., P.D., J.F., F.M.S., Writing - Original Draft, J.R.D.; Writing - Review \& Editing, J.R.D., P.D., N.T., L.M.V., K.E-M., F.M.S.; Visualization, J.R.D., P.D., S.H.R., B.F., K.E-M., F.M.S.;

Supervision, B.D.H., O.F., K.E-M., F.M.S.; Project Administration, F.M.S.; Funding, B.D.H., O.F., K.E-M, F.M.S. 


\section{Figure Legends}

\section{Figure 1. P2-HNF4 $\alpha$ correlates with neither a fetal nor a cancer profile.}

(A) Hnf4a P1 and P2 promoters and first exons in WT and $\alpha 7 \mathrm{HMZ}$ mice, protein products (P1:

HNF4 $\alpha$; P2: HNF4 $\alpha 7$ ) and epitopes for P1-, P2-specific and P1/P2-common antibodies (Abs). DBD, DNA binding domain; LBD, ligand binding domain. (B) Immunoblots (IBs) of nuclear (NE) and whole cell liver extracts (WCE) with P1-specific and P1/P2-HNF4 $\alpha$ Abs. M, molecular weight markers (top band, $54 \mathrm{kD}$ ). COS-7 $\alpha 2$, NE of cells transfected with human HNF $\alpha 2 .(C)$ UCSC Genome Browser view of liver RNA-seq reads mapping to Hnf4a. (D) Number of common and significantly (padj $\leq 0.01$ ) dysregulated genes in WT and $\alpha 7 \mathrm{HMZ}$ male liver RNAseq (10:30 AM, ZT3.5) with baseMean $\geq 10(\mathrm{n}=3)$. (E) Average FPKM of most significantly upand downregulated genes in $\alpha 7 \mathrm{HMZ}$ livers compared to WT. All, padj $<0.01$. $(F)$ Enriched KEGG pathways for WT- and $\alpha 7 \mathrm{HMZ}$-uniquely expressed genes. $(G)$ RNA-seq $\log 2$ foldchange (log2FC) values between WT and $\alpha 7 \mathrm{HMZ}$, plotted against adult and E14.5 fetal mouse livers from ENCODE. Colored data points (total number noted in each quadrant), padj $\leq 0.01$ in both datasets: blue, up in WT; red, up in $\alpha 7 \mathrm{HMZ}$. $(H)$ As in $(G)$ except plotted versus data from murine hepatoma cell line (Hepa1-6) and WT C57BL/6 livers. See Table S1 and Table S2BD for full lists of genes and Figure S1 for additional comparisons.

Figure 2. HNF4 $\alpha$ is one of the most highly expressed TFs in the liver; P2-HNF4a promotes "feminization" of the mouse liver.

(A) Number of genes with significant gene expression changes (padj $\leq 0.01, \log 2 \mathrm{FC} \geq 1$ ) between different time points and $\alpha 7 \mathrm{HMZ}$ and WT in RNA-seq. (B) Differential gene expression at 10:30 AM. Colored spots, $\log 2 \mathrm{FC} \geq 1.75$ (blue, WT; red, $\alpha 7 \mathrm{HMZ}$ ). (C) Average FPKM values 
for the top 85 expressed TFs in WT fed livers at 10:30 AM, sorted by WT FPKM values at 13:30. Arrows, LETFs. * padj $\leq 0.01 .(D, E)$ Average FPKM of indicated genes. $\#$ padj $\leq 0.05$; (\#) $\operatorname{padj}=0.055(\mathrm{p}=0.01) ;{ }^{*}$ padj $\leq 0.01$. See also Figure $\mathrm{S} 2$.

Figure 3. P2-HNF4a dysregulates the expression of genes involved in fatty acid, steroid and xenobiotic/drug metabolism.

(A) Heatmap of row-normalized rlog read counts from RNA-seq for Phase I and II genes (padj $\leq$ 0.01 ) between WT and $\alpha 7 \mathrm{HMZ}$ at any time point. Bottom, level of UDP-glucuronic acid in WT and $\alpha 7 \mathrm{HMZ}$ livers, $* \mathrm{p} \leq 0.01$ by Mann-Whitney. $(B, C, E, F)$ Average FPKM values. * padj $\leq$ 0.01 and $\#$ padj $\leq 0.05$ between $\mathrm{WT}$ and $\alpha 7 \mathrm{HMZ}$ at a given time point. $(D)$ DiHETrE oxylipins (or DHETs, dihydroxytrienoic acid) levels in WT and $\alpha 7 \mathrm{HMZ}$ livers (n=3, 12-13 weeks old), generated from arachidonic acid by CYP2B10 and EPHX2. ${ }^{*} \mathrm{p} \leq 0.01$ by Student's T-test.

Figure 4. HNF4a isoforms exhibit similar but non identical chromatin binding profiles in vivo and in vitro.

(A) Number of common, WT- and $\alpha 7 \mathrm{HMZ}$-unique HNF4 $\alpha$ ChIP-seq peaks. $(B)$ Feature distribution plots from ChIPseeker. (C) WT- and $\alpha 7 \mathrm{HMZ}$-unique ChIP peaks grouped by HNF4 $\alpha$ SVM motif score. TFs corresponding to the top DNA motifs from de novo MEME-ChIP analysis are given. NRs, HNF4 $\alpha$ DR1-like motif. $(D)$ Log2 average binding intensities from PBMs with ectopically expressed human HNF4 $\alpha 8$ versus HNF4 $\alpha 2$ in COS-7 cells, and mouse liver NEs from $\alpha 7 \mathrm{HMZ}$ versus WT. Middle top, test sequences used in PBM design. Middle bottom, PWMs for red and green spots in mouse liver scatterplot, which are mapped back onto COS-7 plots. See also Figures S3 and S4. 
Figure 5. HNF4 $\alpha$ isoforms have unique protein-protein interactions.

(A) Number of genes with one or more WT- or $\alpha 7 \mathrm{HMZ}$-unique ChIP-peaks within a 50-kb of +1 of differentially expressed genes in WT and $\alpha 7 \mathrm{HMZ}$ livers (padj $\leq 0.01) .(B, C) \mathrm{UCSC}$ Genome Browser view of dysregulated genes with a unique ChIP-signal and RNA-seq from 10:30 AM. Axes for WT and $\alpha 7 \mathrm{HMZ}$ signals are set to the same scale but may differ between genes. $(D)$ Top, number of proteins bound to HNF4 $\alpha$ in WT vs. $\alpha 7 \mathrm{HMZ}$ livers at 10:30 (ZT3.5 left), at 20:30 (ZT13.5 right) and in both WT and $\alpha 7 \mathrm{HMZ}$ at 10:30 vs. 20:30 (middle). Bottom, select proteins involved in transcription regulation bound only in WT, $\alpha 7 \mathrm{HMZ}$ or both genotypes. See Table S3 for all interacting proteins and Figure S4D.

Figure 6. HNF4 $\alpha$ isoforms differentially impact diurnal gene expression

(A) Heatmap of rlog read counts for all circadian-regulated and core clock genes with padj $\leq$ 0.01 and $\log 2 \mathrm{FC} \geq 2$ between any pair of time points. $(B)$ Average FPKM of select circadian clock genes. \# padj $\leq 0.05$; * padj $\leq 0.01$. (C) Sample distance matrix for each RNA-seq replicate, calculated across the full transcriptome. The darker the color, the higher the degree of similarity. (D) Relative fold increase in P1- and P2-HNF4a in livers of WT or littermate Clock KO by qRT-PCR at indicated ZT. Two-way ANOVA, Sidak's multiple comparisons test, \# $\mathrm{p} \leq$ $0.05 ; * * \mathrm{p} \leq 0.005$. Error bars, SEM $(\mathrm{n}=3-4)$. (E) IB of diurnal expression of P2-HNF4 $\alpha$ protein in WCE from WT and Clock KO livers using P2-specific antibodies. See also Figure S5.

Figure 7. P1-HNF4a drives gluconeogenesis while P2-HNF4a drives ketogenesis; both are required for homeostasis in carbohydrate and lipid metabolism. 
(A) Number of primary metabolites and complex lipids in WT and $\alpha 7 \mathrm{HMZ}$ livers of fed mice at 10:30 AM ( $\mathrm{n}=8)$. Uniqueness identified by Mann-Whitney U-test $(\mathrm{p} \leq 0.05)$. (B) Primary metabolites related to Krebs cycle and ketogenesis (a single mouse outlier was omitted for both the WT and $\alpha 7 \mathrm{HMZ}$ datasets for a final $\mathrm{n}=7)$ and known complex lipids $(\mathrm{n}=8)(C)$. Student's Ttest: $\# \mathrm{p} \leq 0.05 ; * \mathrm{p} \leq 0.01$. (D) Number of genes dysregulated (padj $\leq 0.01)$ in fed vs. fasted (12 hr) WT and $\alpha 7 \mathrm{HMZ}$ livers (10:30 AM). (E) Liver-to-body weight ratios in fed and fasted WT and $\alpha 7 \mathrm{HMZ}$ mice $(\mathrm{n}=9-14) .{ }^{*} \mathrm{p} \leq 0.01$ by Student's T-test, excluding outliers (gray dots). $(F)$ Percent survival of WT, $\alpha 1 \mathrm{HMZ}$ and $\alpha 7 \mathrm{HMZ}$ male mice ( $\sim 20 \mathrm{wks})$ during a prolonged fast $(\mathrm{n}=5-6) .(G) \beta$-hydroxybutyric acid levels in blood of WT, $\alpha 7 \mathrm{HMZ}$ and $\alpha 1 \mathrm{HMZ}$ during a $60-\mathrm{hr}$ fast (left) $(n=3-5)$ and at ZT23 and ZT11 after 1 week of restricted feeding (food removed between ZT0 and ZT12) (right) $(\mathrm{n}=6-8)$. Student's T-test: \# $\mathrm{p}<0.05$ vs. other two genotypes; $\$$ $\mathrm{p}<0.05$ vs. $\alpha 1 \mathrm{HMZ}$ females at the same time point; $\& \mathrm{p}<0.05$ vs. males of same genotype at ZT11; @ $<<0.05$ vs. females of the same genotype at ZT11; $€ p<0.05$ vs. WT and $\alpha 1 \mathrm{HMZ}$ males at ZT23. $(H, I)$ Models discussed in text. See also Figures S6 and S7. 


\section{References}

Argemi, J., Latasa, M.U., Atkinson, S.R., Blokhin, I.O., Massey, V., Gue, J.P., Cabezas, J., Lozano, J.J., Van Booven, D., Bell, A., et al. (2019). Defective HNF4alpha-dependent gene expression as a driver of hepatocellular failure in alcoholic hepatitis. Nat. Commun. 10, 3126.

Bailly, A., Briançon, N., and Weiss, M.C. (2009). Characterization of glucocorticoid receptor and hepatocyte nuclear factor 4alpha (HNF4alpha) binding to the hnf4alpha gene in the liver. Biochimie 91, 1095-1103.

Battle, M.A., Konopka, G., Parviz, F., Gaggl, A.L., Yang, C., Sladek, F.M., and Duncan, S.A. (2006). Hepatocyte nuclear factor 4alpha orchestrates expression of cell adhesion proteins during the epithelial transformation of the developing liver. Proc. Natl. Acad. Sci. U. S. A. 103, 84198424.

Bolotin, E., Liao, H., Ta, T.C., Yang, C., Hwang-Verslues, W., Evans, J.R., Jiang, T., and Sladek, F.M. (2010). Integrated approach for the identification of human hepatocyte nuclear factor 4alpha target genes using protein binding microarrays. Hepatology 51, 642-653.

Bolotin, E., Chellappa, K., Hwang-Verslues, W., Schnabl, J.M., Yang, C., and Sladek, F.M. (2011). Nuclear Receptor HNF4a Binding Sequences are Widespread in Alu Repeats. BMC Genomics 12, 560.

Briançon, N., and Weiss, M.C. (2006). In vivo role of the HNF4 $\alpha$ AF-1 activation domain revealed by exon swapping. EMBO J. 25, 1253-1262.

Briançon, N., Bailly, A., Clotman, F., Jacquemin, P., Lemaigre, F.P., and Weiss, M.C. (2004). Expression of the alpha7 isoform of hepatocyte nuclear factor (HNF) 4 is activated by HNF6/OC-2 and HNF1 and repressed by HNF4alpha1 in the liver. J. Biol. Chem. 279, 3339833408 .

Cai, S.-H., Lu, S.-X., Liu, L.-L., Zhang, C.Z., and Yun, J.-P. (2017). Increased expression of hepatocyte nuclear factor 4 alpha transcribed by promoter 2 indicates a poor prognosis in hepatocellular carcinoma. Therap. Adv. Gastroenterol. 10, 761-771.

Chavan, R., Feillet, C., Costa, S.S.F., Delorme, J.E., Okabe, T., Ripperger, J.A., and Albrecht, U. (2016). Liver-derived ketone bodies are necessary for food anticipation. Nat. Commun. 7, 10580.

Chen, T.-Y., Li, Y.-C., Liu, Y.-F., Tsai, C.-M., Hsieh, Y.-H., Lin, C.-W., Yang, S.-F., and Weng, C.-J. (2011). Role of MMP14 gene polymorphisms in susceptibility and pathological development to hepatocellular carcinoma. Ann. Surg. Oncol. 18, 2348-2356.

Chen, Z., Wu, G., Ye, F., Chen, G., Fan, Q., Dong, H., Zhu, X., and Wu, C. (2019). High expression of MMP19 is associated with poor prognosis in patients with colorectal cancer. BMC Cancer 19, 448.

Clodfelter, K.H., Miles, G.D., Wauthier, V., Holloway, M.G., Zhang, X., Hodor, P., Ray, W.J., and Waxman, D.J. (2007). Role of STAT5a in regulation of sex-specific gene expression in female but not male mouse liver revealed by microarray analysis. Physiol. Genomics 31, 63-74. 
Conforto, T.L., and Waxman, D.J. (2012). Sex-specific mouse liver gene expression: genomewide analysis of developmental changes from pre-pubertal period to young adulthood. Biol. Sex Differ. 3, 9.

Debruyne, J.P., Noton, E., Lambert, C.M., Maywood, E.S., Weaver, D.R., and Reppert, S.M. (2006). A clock shock: mouse CLOCK is not required for circadian oscillator function. Neuron $50,465-477$.

Deol, P., Fahrmann, J., Yang, J., Evans, J.R., Rizo, A., Grapov, D., Salemi, M., Wanichthanarak, K., Fiehn, O., Phinney, B., et al. (2017). Omega-6 and omega-3 oxylipins are implicated in soybean oil-induced obesity in mice. Sci. Rep. 7, 12488.

Eckel-Mahan, K.L., Patel, V.R., Mohney, R.P., Vignola, K.S., Baldi, P., and Sassone-Corsi, P. (2012). Coordination of the transcriptome and metabolome by the circadian clock. Proc. Natl. Acad. Sci. U. S. A. 109, 5541-5546.

Eckel-Mahan, K.L., Patel, V.R., de Mateo, S., Orozco-Solis, R., Ceglia, N.J., Sahar, S., DilagPenilla, S.A., Dyar, K.A., Baldi, P., and Sassone-Corsi, P. (2013). Reprogramming of the circadian clock by nutritional challenge. Cell 155, 1464-1478.

Fekry, B., Ribas-Latre, A., Baumgartner, C., Deans, J.R., Kwok, C., Patel, P., Fu, L., Berdeaux, R., Sun, K., Kolonin, M.G., et al. (2018). Incompatibility of the circadian protein BMAL1 and $\mathrm{HNF} 4 \alpha$ in hepatocellular carcinoma. Nat. Commun. 9, 4349.

Halkes, C.J.M., van Dijk, H., Verseyden, C., de Jaegere, P.P.T., Plokker, H.W.M., Meijssen, S., Erkelens, D.W., and Cabezas, M.C. (2003). Gender differences in postprandial ketone bodies in normolipidemic subjects and in untreated patients with familial combined hyperlipidemia. Arterioscler. Thromb. Vasc. Biol. 23, 1875-1880.

Hall, R.K., Sladek, F.M., and Granner, D.K. (1995). The orphan receptors COUP-TF and HNF-4 serve as accessory factors required for induction of phosphoenolpyruvate carboxykinase gene transcription by glucocorticoids. Proc. Natl. Acad. Sci. U. S. A. 92, 412-416.

Hatziapostolou, M., Polytarchou, C., Aggelidou, E., Drakaki, A., Poultsides, G.A., Jaeger, S.A., Ogata, H., Karin, M., Struhl, K., Hadzopoulou-Cladaras, M., et al. (2011). An HNF4 $\alpha$-miRNA inflammatory feedback circuit regulates hepatocellular oncogenesis. Cell 147, 1233-1247.

Hayhurst, G.P., Lee, Y.H., Lambert, G., Ward, J.M., and Gonzalez, F.J. (2001). Hepatocyte nuclear factor 4alpha (nuclear receptor 2A1) is essential for maintenance of hepatic gene expression and lipid homeostasis. Mol. Cell. Biol. 21, 1393-1403.

Hernandez, J.P., Chapman, L.M., Kretschmer, X.C., and Baldwin, W.S. (2006). Gender-specific induction of cytochrome P450s in nonylphenol-treated FVB/NJ mice. Toxicol. Appl. Pharmacol. 216, 186-196.

Hirao, J., Nishimura, M., Arakawa, S., Niino, N., Mori, K., Furukawa, T., Sanbuissho, A., Manabe, S., Nishihara, M., and Mori, Y. (2011). Sex and circadian modulatory effects on rat liver as assessed by transcriptome analyses. J. Toxicol. Sci. 36, 9-22. 
Hock, M.B., and Kralli, A. (2009). Transcriptional control of mitochondrial biogenesis and function. Annu. Rev. Physiol. 71, 177-203.

Holloway, M.G., Miles, G.D., Dombkowski, A.A., and Waxman, D.J. (2008). Liver-specific hepatocyte nuclear factor-4alpha deficiency: greater impact on gene expression in male than in female mouse liver. Mol. Endocrinol. 22, 1274-1286.

Huang, A., and Sun, D. (2018). Sexually Dimorphic Regulation of EET Synthesis and Metabolism: Roles of Estrogen. Front. Pharmacol. 9, 1222.

Hwang-Verslues, W.W., and Sladek, F.M. (2008). Nuclear receptor hepatocyte nuclear factor 4alpha1 competes with oncoprotein c-Myc for control of the p21/WAF1 promoter. Mol. Endocrinol. 22, 78-90.

Hwang-Verslues, W.W., and Sladek, F.M. (2010). HNF4 $\alpha$--role in drug metabolism and potential drug target? Curr. Opin. Pharmacol. 10, 698-705.

Ikaga, R., Namekata, I., Kotiadis, V.N., Ogawa, H., Duchen, M.R., Tanaka, H., and Iida-Tanaka, N. (2015). Knockdown of aquaporin-8 induces mitochondrial dysfunction in 3T3-L1 cells.

Biochem Biophys Rep 4, 187-195.

Jiang, G., Nepomuceno, L., Hopkins, K., and Sladek, F.M. (1995). Exclusive homodimerization of the orphan receptor hepatocyte nuclear factor 4 defines a new subclass of nuclear receptors. Mol. Cell. Biol. 15, 5131-5143.

Kamiya, A., Inoue, Y., and Gonzalez, F.J. (2003). Role of the hepatocyte nuclear factor 4alpha in control of the pregnane $\mathrm{X}$ receptor during fetal liver development. Hepatology 37, 1375-1384.

Kardassis, D., Falvey, E., Tsantili, P., Hadzopoulou-Cladaras, M., and Zannis, V. (2002). Direct physical interactions between HNF-4 and Sp1 mediate synergistic transactivation of the apolipoprotein CIII promoter. Biochemistry 41, 1217-1228.

Kettner, N.M., Voicu, H., Finegold, M.J., Coarfa, C., Sreekumar, A., Putluri, N., Katchy, C.A., Lee, C., Moore, D.D., and Fu, L. (2016). Circadian Homeostasis of Liver Metabolism Suppresses Hepatocarcinogenesis. Cancer Cell 30, 909-924.

Lee, Y.K., Dell, H., Dowhan, D.H., Hadzopoulou-Cladaras, M., and Moore, D.D. (2000). The orphan nuclear receptor SHP inhibits hepatocyte nuclear factor 4 and retinoid $\mathrm{X}$ receptor transactivation: two mechanisms for repression. Mol. Cell. Biol. 20, 187-195.

Lu, H. (2016). Crosstalk of HNF4 $\alpha$ with extracellular and intracellular signaling pathways in the regulation of hepatic metabolism of drugs and lipids. Acta Pharm Sin B 6, 393-408.

Lu, Y., Li, N., Gao, L., Xu, Y.-J., Huang, C., Yu, K., Ling, Q., Cheng, Q., Chen, S., Zhu, M., et al. (2016). Acetylcarnitine Is a Candidate Diagnostic and Prognostic Biomarker of Hepatocellular Carcinoma. Cancer Res. 76, 2912-2920.

Maeda, Y., Rachez, C., Hawel, L., 3rd, Byus, C.V., Freedman, L.P., and Sladek, F.M. (2002). Polyamines modulate the interaction between nuclear receptors and vitamin D receptor- 
interacting protein 205. Mol. Endocrinol. 16, 1502-1510.

Marinou, K., Adiels, M., Hodson, L., Frayn, K.N., Karpe, F., and Fielding, B.A. (2011). Young women partition fatty acids towards ketone body production rather than VLDL-TAG synthesis, compared with young men. Br. J. Nutr. 105, 857-865.

Matyash, V., Liebisch, G., Kurzchalia, T.V., Shevchenko, A., and Schwudke, D. (2008). Lipid extraction by methyl-tert-butyl ether for high-throughput lipidomics. J. Lipid Res. 49, 11371146.

Mohammed, H., Taylor, C., Brown, G.D., Papachristou, E.K., Carroll, J.S., and D’Santos, C.S. (2016). Rapid immunoprecipitation mass spectrometry of endogenous proteins (RIME) for analysis of chromatin complexes. Nat. Protoc. 11, 316-326.

Nakhei, H., Lingott, A., Lemm, I., and Ryffel, G.U. (1998). An alternative splice variant of the tissue specific transcription factor HNF4alpha predominates in undifferentiated murine cell types. Nucleic Acids Res. 26, 497-504.

Nassir, F., and Ibdah, J.A. (2016). Sirtuins and nonalcoholic fatty liver disease. World J. Gastroenterol. 22, 10084-10092.

Ning, B.-F., Ding, J., Yin, C., Zhong, W., Wu, K., Zeng, X., Yang, W., Chen, Y.-X., Zhang, J.P., Zhang, X., et al. (2010). Hepatocyte nuclear factor 4 alpha suppresses the development of hepatocellular carcinoma. Cancer Res. 70, 7640-7651.

Oshida, K., Vasani, N., Waxman, D.J., and Corton, J.C. (2016). Disruption of STAT5bRegulated Sexual Dimorphism of the Liver Transcriptome by Diverse Factors Is a Common Event. PLoS One 11, e0148308.

Puchalska, P., and Crawford, P.A. (2017). Multi-dimensional Roles of Ketone Bodies in Fuel Metabolism, Signaling, and Therapeutics. Cell Metab. 25, 262-284.

Qu, M., Duffy, T., Hirota, T., and Kay, S.A. (2018). Nuclear receptor HNF4A transrepresses CLOCK:BMAL1 and modulates tissue-specific circadian networks. Proc. Natl. Acad. Sci. U. S. A. 115, E12305-E12312.

Rando, G., Tan, C.K., Khaled, N., Montagner, A., Leuenberger, N., Bertrand-Michel, J., Paramalingam, E., Guillou, H., and Wahli, W. (2016). Glucocorticoid receptor-PPAR $\alpha$ axis in fetal mouse liver prepares neonates for milk lipid catabolism. Elife 5.

Ribas-Latre, A., and Eckel-Mahan, K. (2016). Interdependence of nutrient metabolism and the circadian clock system: Importance for metabolic health. Mol Metab 5, 133-152.

Risso, D., Schwartz, K., Sherlock, G., and Dudoit, S. (2011). GC-content normalization for RNA-Seq data. BMC Bioinformatics 12, 480.

Robles, M.S., Cox, J., and Mann, M. (2014). In-vivo quantitative proteomics reveals a key contribution of post-transcriptional mechanisms to the circadian regulation of liver metabolism. PLoS Genet. 10, e1004047. 
Rodríguez, J.C., Ortiz, J.A., Hegardt, F.G., and Haro, D. (1998). The hepatocyte nuclear factor 4 (HNF-4) represses the mitochondrial HMG-CoA synthase gene. Biochem. Biophys. Res. Commun. 242, 692-696.

Ruse, M.D., Jr, Privalsky, M.L., and Sladek, F.M. (2002). Competitive cofactor recruitment by orphan receptor hepatocyte nuclear factor 4alpha1: modulation by the F domain. Mol. Cell. Biol. $22,1626-1638$.

Sladek, F.M., Zhong, W.M., Lai, E., and Darnell, J.E., Jr (1990). Liver-enriched transcription factor HNF-4 is a novel member of the steroid hormone receptor superfamily. Genes Dev. 4, $2353-2365$.

Sladek, F.M., Ruse, M.D., Jr, Nepomuceno, L., Huang, S.M., and Stallcup, M.R. (1999). Modulation of transcriptional activation and coactivator interaction by a splicing variation in the F domain of nuclear receptor hepatocyte nuclear factor 4alpha1. Mol. Cell. Biol. 19, 6509-6522.

Tahara, Y., and Shibata, S. (2016). Circadian rhythms of liver physiology and disease: experimental and clinical evidence. Nat. Rev. Gastroenterol. Hepatol. 13, 217-226.

Takahashi, S., Matsuura, N., Kurokawa, T., Takahashi, Y., and Miura, T. (2002). Co-operation of the transcription factor hepatocyte nuclear factor-4 with Sp1 or Sp3 leads to transcriptional activation of the human haem oxygenase- 1 gene promoter in a hepatoma cell line. Biochem. $J$ $367,641-652$.

Tanaka, T., Jiang, S., Hotta, H., Takano, K., Iwanari, H., Sumi, K., Daigo, K., Ohashi, R., Sugai, M., Ikegame, C., et al. (2006). Dysregulated expression of P1 and P2 promoter-driven hepatocyte nuclear factor-4alpha in the pathogenesis of human cancer. J. Pathol. 208, 662-672.

Tognini, P., Murakami, M., Liu, Y., Eckel-Mahan, K.L., Newman, J.C., Verdin, E., Baldi, P., and Sassone-Corsi, P. (2017). Distinct Circadian Signatures in Liver and Gut Clocks Revealed by Ketogenic Diet. Cell Metab. 26, 523-538.e5.

Tolson, A.H., and Wang, H. (2010). Regulation of drug-metabolizing enzymes by xenobiotic receptors: PXR and CAR. Adv. Drug Deliv. Rev. 62, 1238-1249.

Torres-Padilla, M.E., Fougere-Deschatrette, C., and Weiss, M.C. (2001). Expression of HNF4a isoforms in mouse liver development is regulated by sequential promoter usage and constitutive 3 end splicing. Mech. Dev. 109, 183-193.

Torres-Padilla, M.E., Sladek, F.M., and Weiss, M.C. (2002). Developmentally regulated Nterminal variants of the nuclear receptor hepatocyte nuclear factor 4alpha mediate multiple interactions through coactivator and corepressor-histone deacetylase complexes. J. Biol. Chem. $277,44677-44687$.

Verzi, M.P., Shin, H., He, H.H., Sulahian, R., Meyer, C.A., Montgomery, R.K., Fleet, J.C., Brown, M., Liu, X.S., and Shivdasani, R.A. (2010). Differentiation-specific histone modifications reveal dynamic chromatin interactions and partners for the intestinal transcription factor CDX2. Dev. Cell 19, 713-726. 
Vuong, L.M., Chellappa, K., Dhahbi, J.M., Deans, J.R., Fang, B., Bolotin, E., Titova, N.V., Hoverter, N.P., Spindler, S.R., Waterman, M.L., et al. (2015). Differential Effects of Hepatocyte Nuclear Factor $4 \alpha$ Isoforms on Tumor Growth and T-Cell Factor 4/AP-1 Interactions in Human Colorectal Cancer Cells. Mol. Cell. Biol. 35, 3471-3490.

Wagner, K., Inceoglu, B., and Hammock, B.D. (2011). Soluble epoxide hydrolase inhibition, epoxygenated fatty acids and nociception. Prostaglandins Other Lipid Mediat. 96, 76-83.

Walesky, C., and Apte, U. (2015). Role of hepatocyte nuclear factor $4 \alpha(\mathrm{HNF} 4 \alpha)$ in cell proliferation and cancer. Gene Expr. 16, 101-108.

Walesky, C., Gunewardena, S., Terwilliger, E.F., Edwards, G., Borude, P., and Apte, U. (2013). Hepatocyte-specific deletion of hepatocyte nuclear factor- $4 \alpha$ in adult mice results in increased hepatocyte proliferation. Am. J. Physiol. Gastrointest. Liver Physiol. 304, G26-G37.

Wiwi, C.A., Gupte, M., and Waxman, D.J. (2004). Sexually dimorphic P450 gene expression in liver-specific hepatocyte nuclear factor 4alpha-deficient mice. Mol. Endocrinol. 18, 1975-1987.

Xia, J., and Wishart, D.S. (2002). Using MetaboAnalyst 3.0 for Comprehensive Metabolomics Data Analysis. In Current Protocols in Bioinformatics, (John Wiley \& Sons, Inc.),.

Yaligar, J., Teoh, W.W., Othman, R., Verma, S.K., Phang, B.H., Lee, S.S., Wang, W.W., Toh, H.C., Gopalan, V., Sabapathy, K., et al. (2016). Longitudinal metabolic imaging of hepatocellular carcinoma in transgenic mouse models identifies acylcarnitine as a potential biomarker for early detection. Sci. Rep. 6, 20299.

Yang, J., Schmelzer, K., Georgi, K., and Hammock, B.D. (2009). Quantitative profiling method for oxylipin metabolome by liquid chromatography electrospray ionization tandem mass spectrometry. Anal. Chem. 81, 8085-8093.

Yuan, X., Ta, T.C., Lin, M., Evans, J.R., Dong, Y., Bolotin, E., Sherman, M.A., Forman, B.M., and Sladek, F.M. (2009). Identification of an endogenous ligand bound to a native orphan nuclear receptor. PLoS One 4, e5609.

Zhao, X., Cho, H., Yu, R.T., Atkins, A.R., Downes, M., and Evans, R.M. (2014). Nuclear receptors rock around the clock. EMBO Rep. 15, 518-528.

Zheng, S., Wu, H., Wang, F., Lv, J., Lu, J., Fang, Q., Wang, F., Lu, Y., Zhang, S., Xu, Y., et al. (2019). The oncoprotein HBXIP facilitates metastasis of hepatocellular carcinoma cells by activation of MMP15 expression. Cancer Manag. Res. 11, 4529-4540. 
A

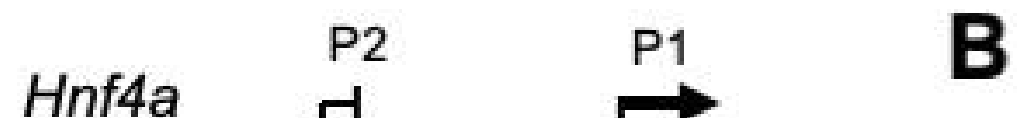

Deans_Fig1

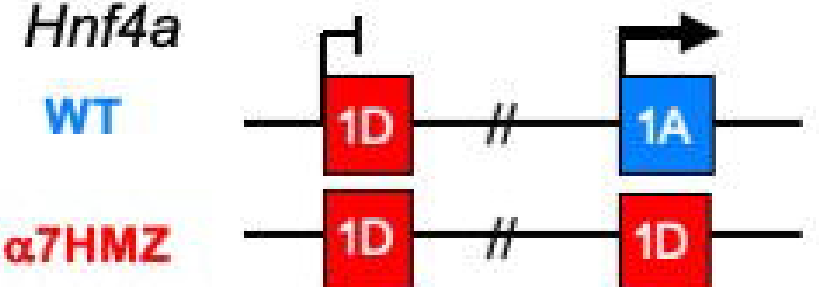

Adult

Fetal

\section{aP1 aP1/P2}

$\cos -7$

Adult Liver NE

HNF4a2 WT

a7HMZ

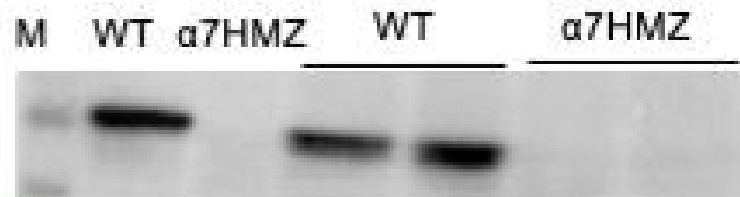

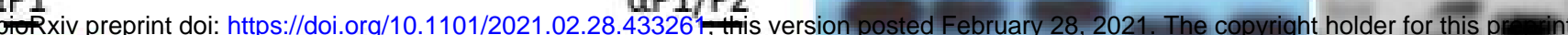

$\mathrm{P} 1(\alpha 1)$

P2 ( $\alpha 7)$

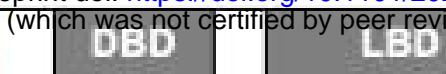

D
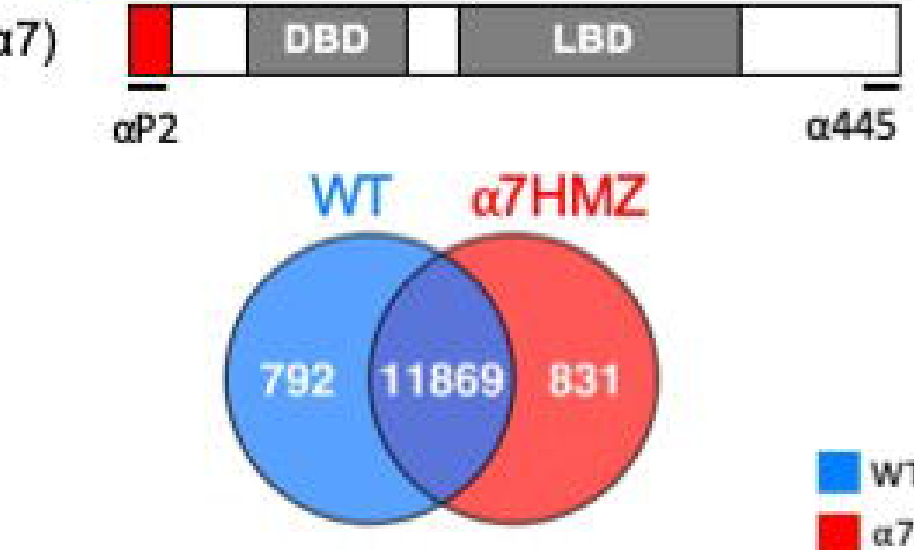

Exon 1D

Exon $1 \mathrm{~A}$

Exon 2

$\alpha 7 \mathrm{HMZ} \quad 600$

-

WT 600

Hnf4a

WT
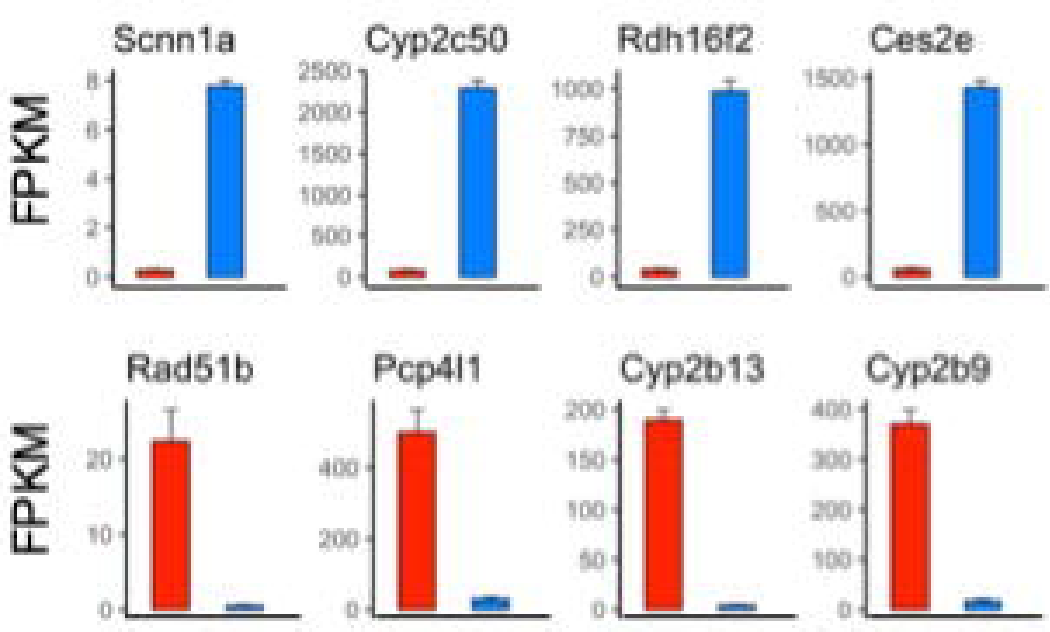

$\mathbf{F}$
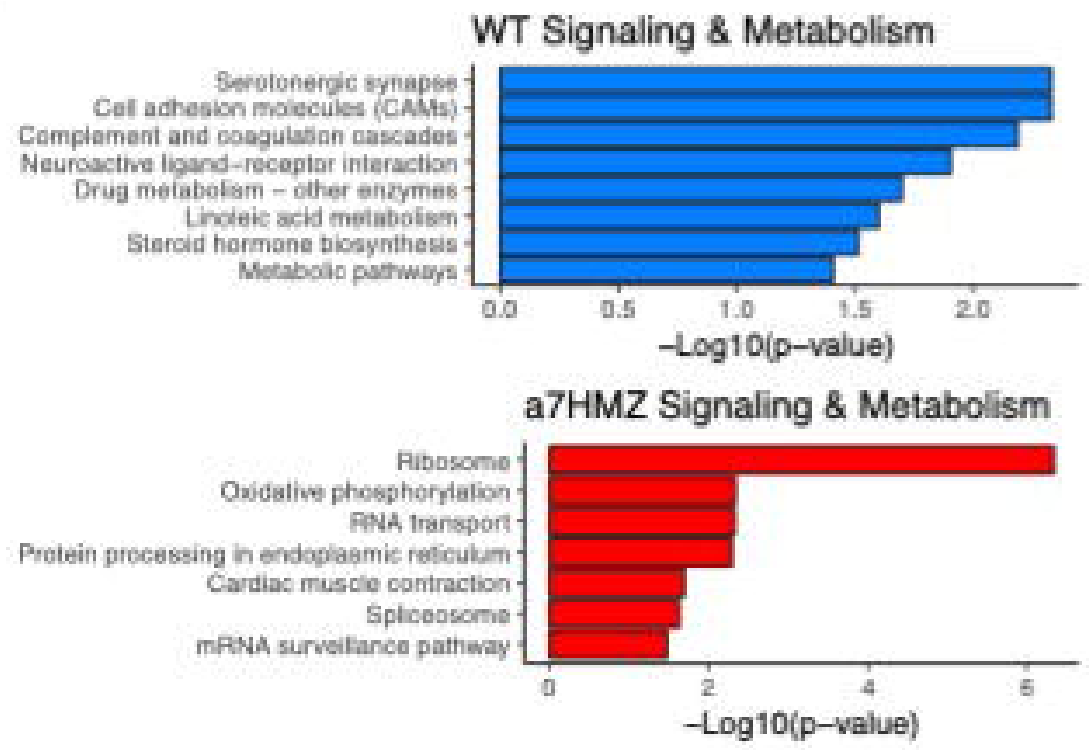

a7HMZ Disease

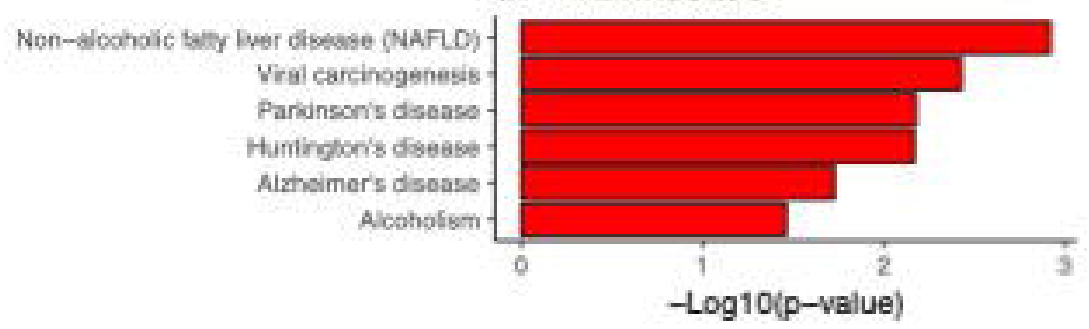

H
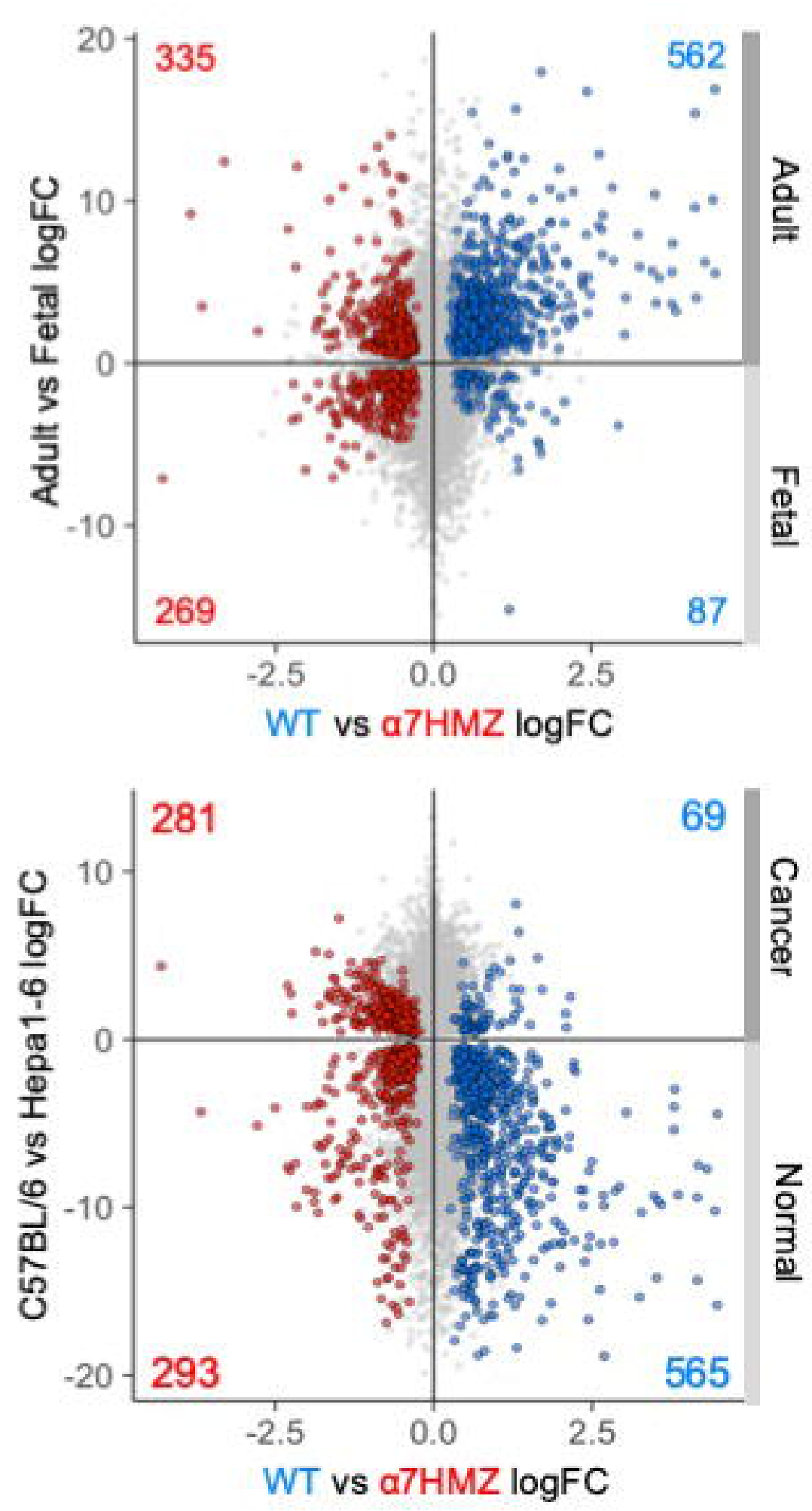
$\mathbf{A}$

Hour $7 \quad 10: 30 \quad 13: 30 \quad 19 \quad 20: 30$

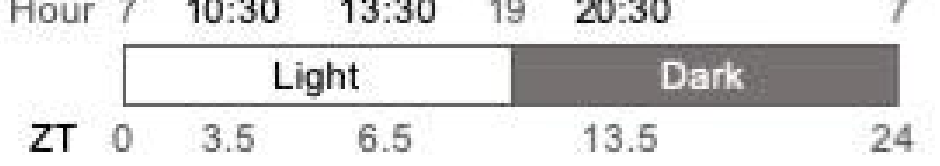

bioRxiv preprint doi: https://doi.org/10.1101/2021.02.28.433261; this version posted February 28, 2021. The copyright holder for this preprint (which was not certified by peer review) is the author/funder. All rights reserved. No reuse allowed without permission.

WT

$10: 30$ vs $10: 30$ vs $13: 30$ vs

a7HMZ

\begin{tabular}{ccc}
$13: 30$ & $20: 30$ & $20: 30$ \\
\hline 271 & 509 & 252
\end{tabular}

225

158

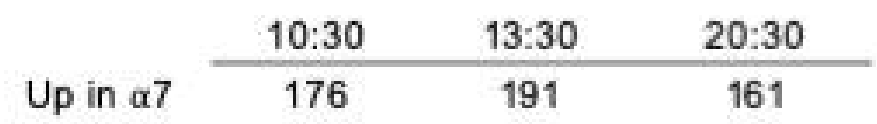

Down in $\alpha 7$

Total

\begin{tabular}{lll}
289 & 245 & 260 \\
\hline 465 & 436 & 421
\end{tabular}

150
B

WT vs $\alpha 7 \mathrm{HMZ} @ 10: 30$ AM

Rdh16f2

뭄
음
음

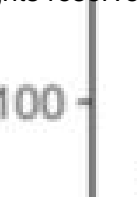

,

$\mid \begin{array}{ll}\text { \& } & \text { WT } \\ & \text { a7HMZ }\end{array}$

C

$\left.\sum_{\frac{8}{2}}^{2000-}\right]_{l}^{*}$

D
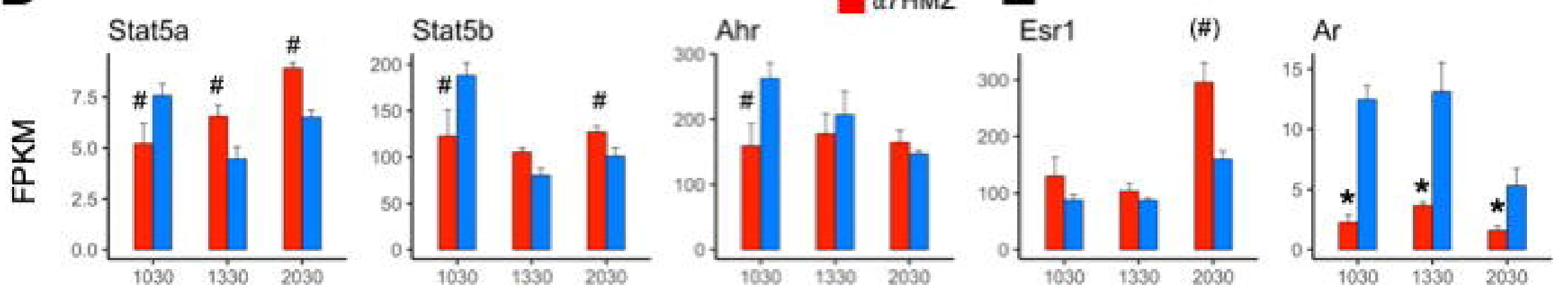
A

Cyp Genes

B C

$\mathrm{Nr} 1 \mathrm{i} 3$

Cyp2b10

Ephx2 $\quad \alpha 7 \mathrm{HMZ}$
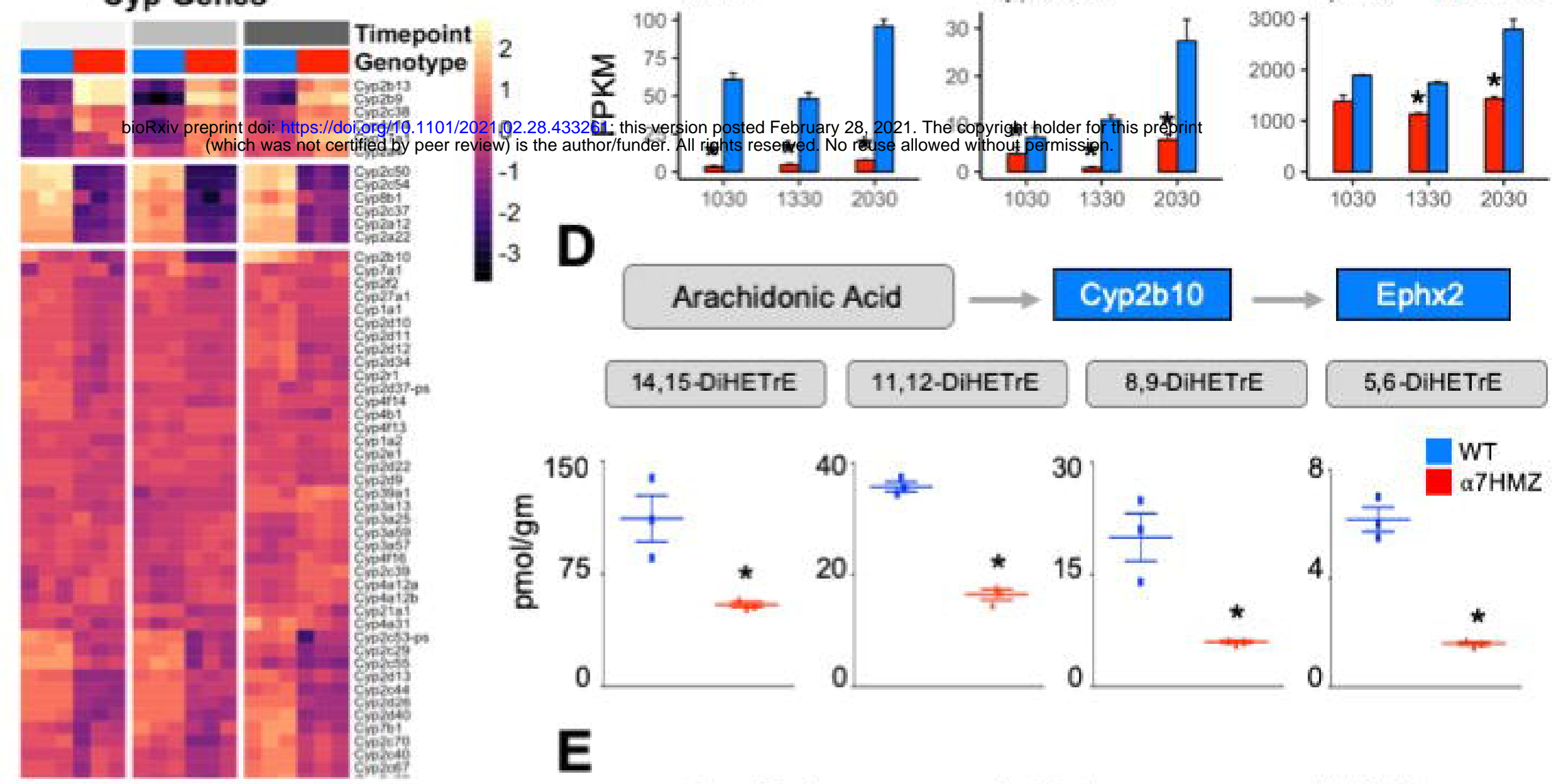

$\begin{array}{ll}-2 & \mathbf{D}\end{array}$
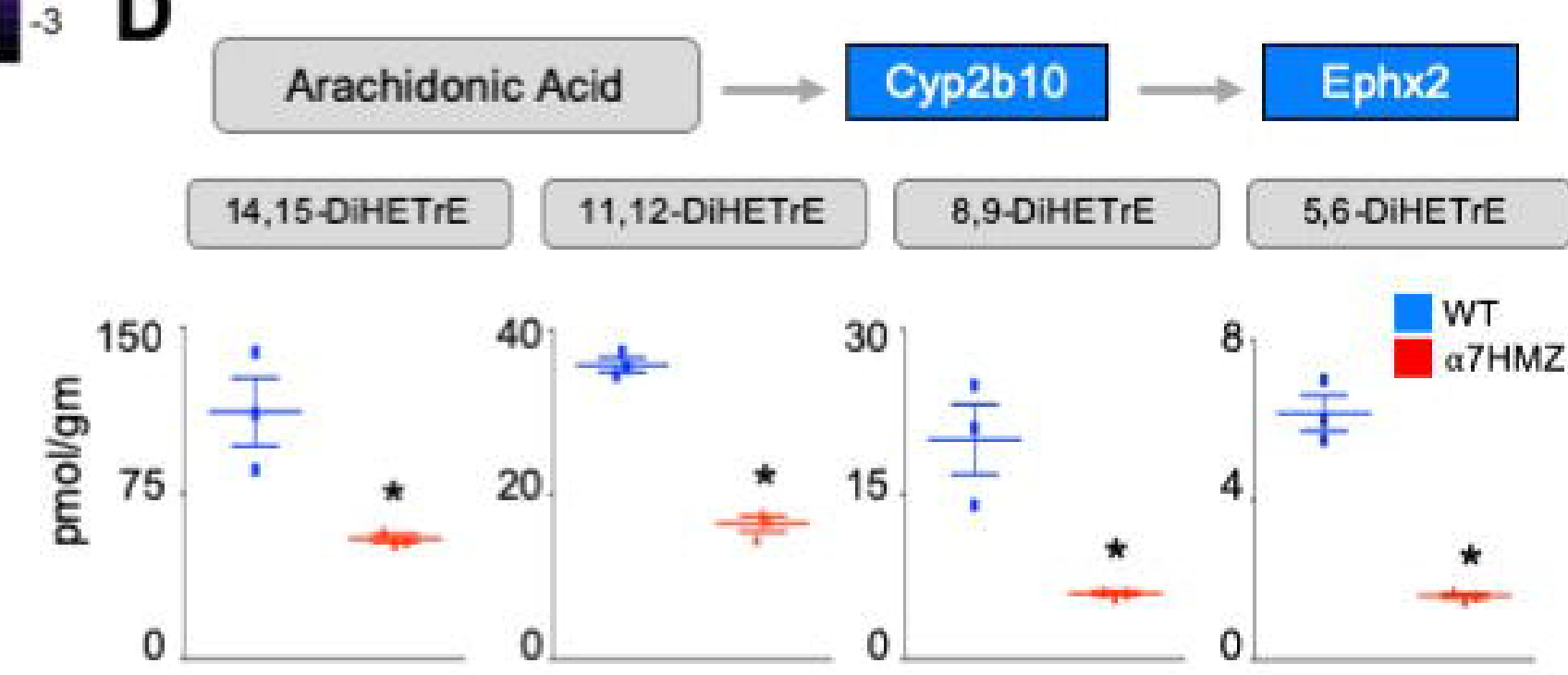

Gst Genes

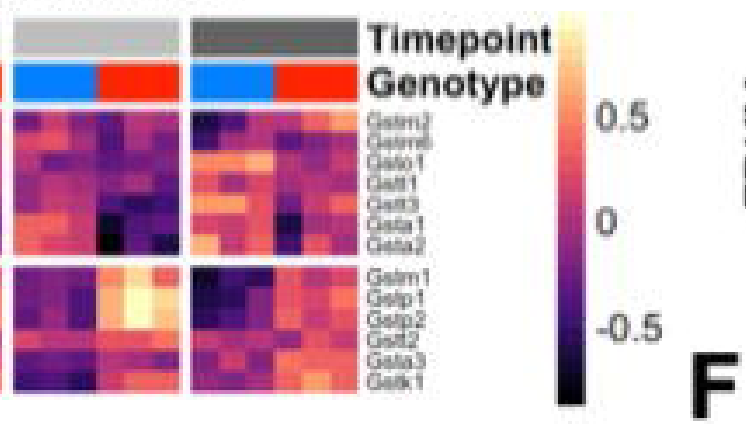

\section{Ugt Genes}
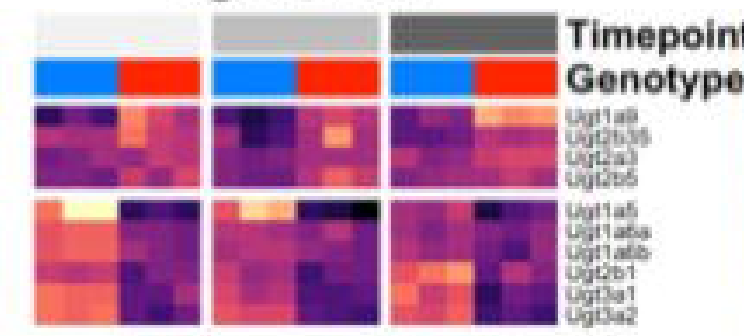

UDP-glucuronic acid

Timepoint

$10: 30$
$+13: 30$

20:30

Genotype

WT

c/7HMZ

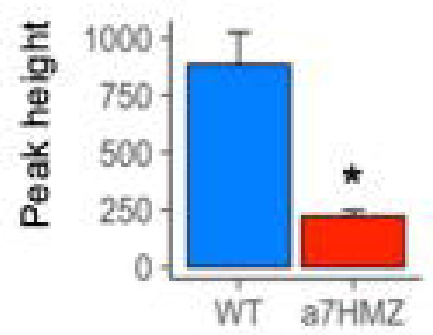

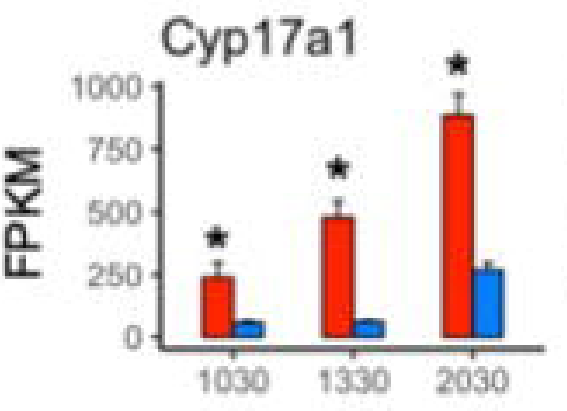

Srd5a1

Hsd3b5

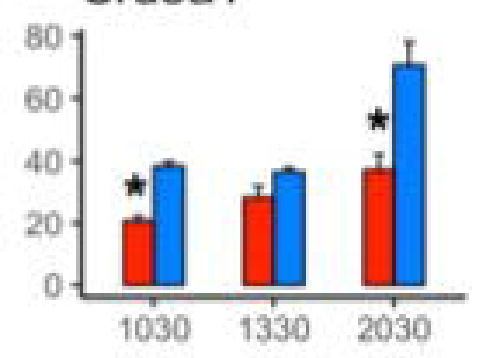

Сур2b13
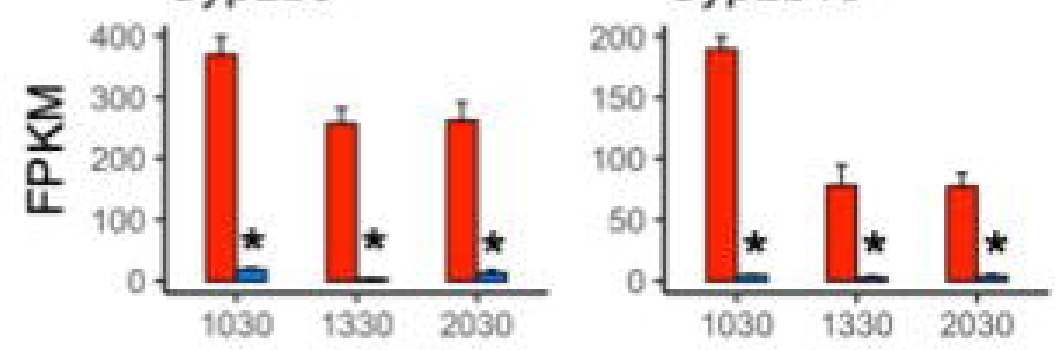

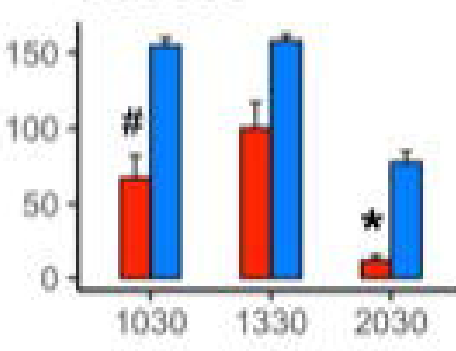

\section{Сyp2a4}

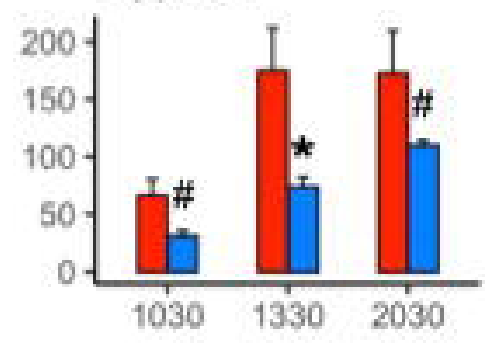




\section{Deans_Fig4}

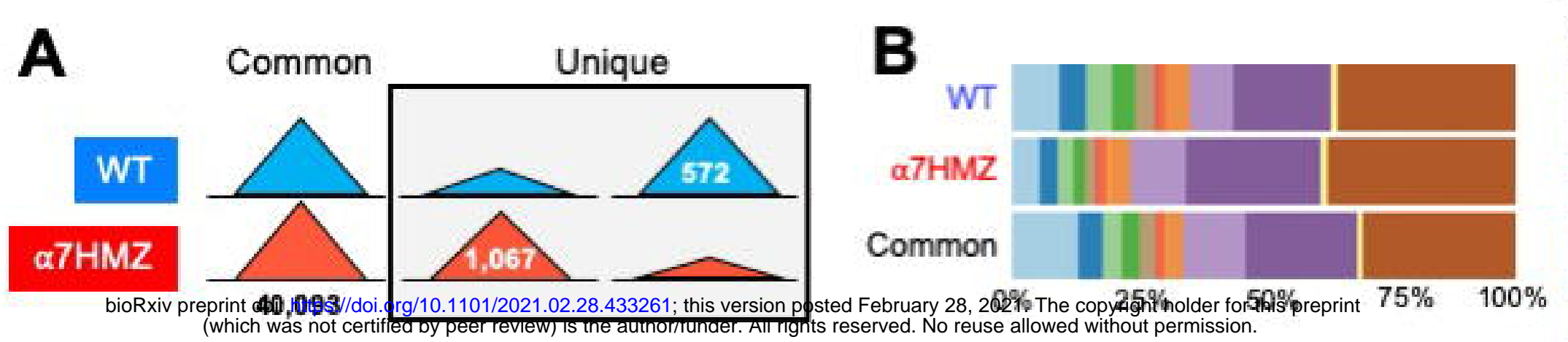

C (which was not certified toypeer review) Is the authortunder. All rignts reserved. No reuse allowed without permission.

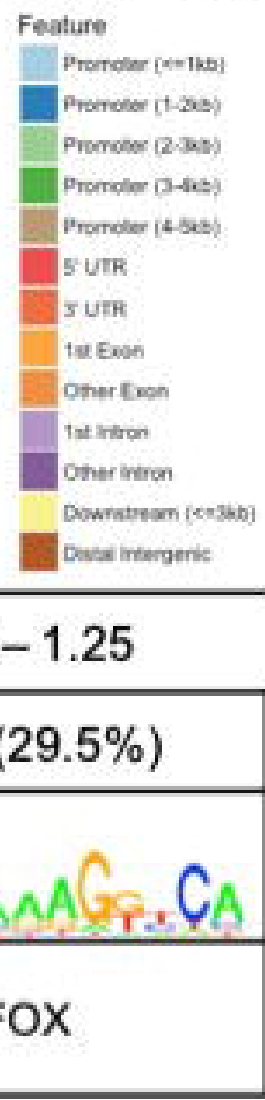

$\alpha 7 \mathrm{HMZ}(1,067)$

\# Peaks

SVM Motif

Transcription

Factor

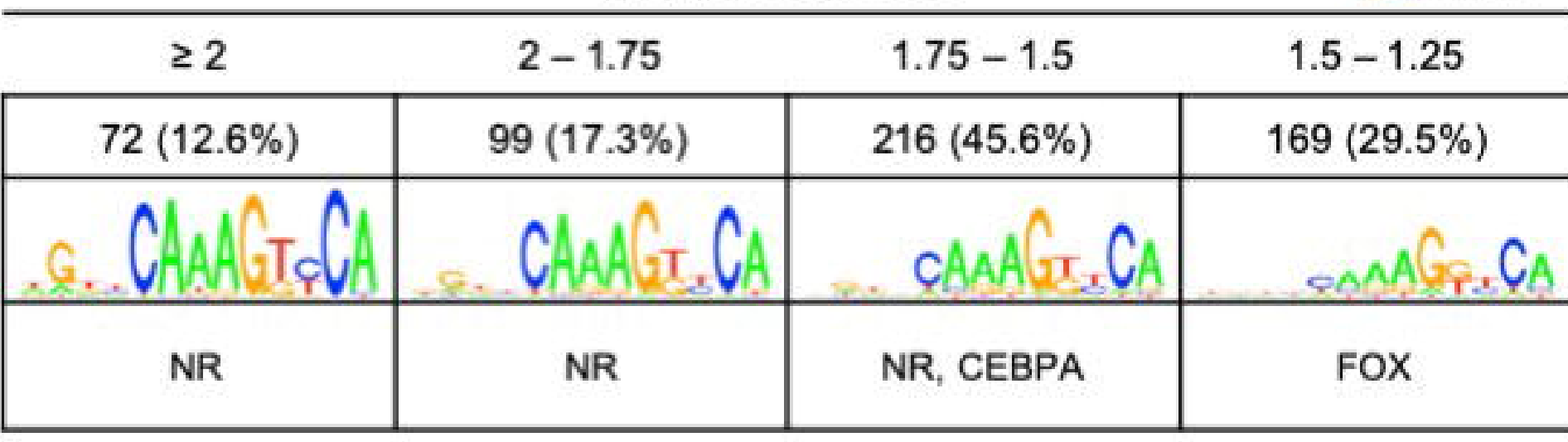

D

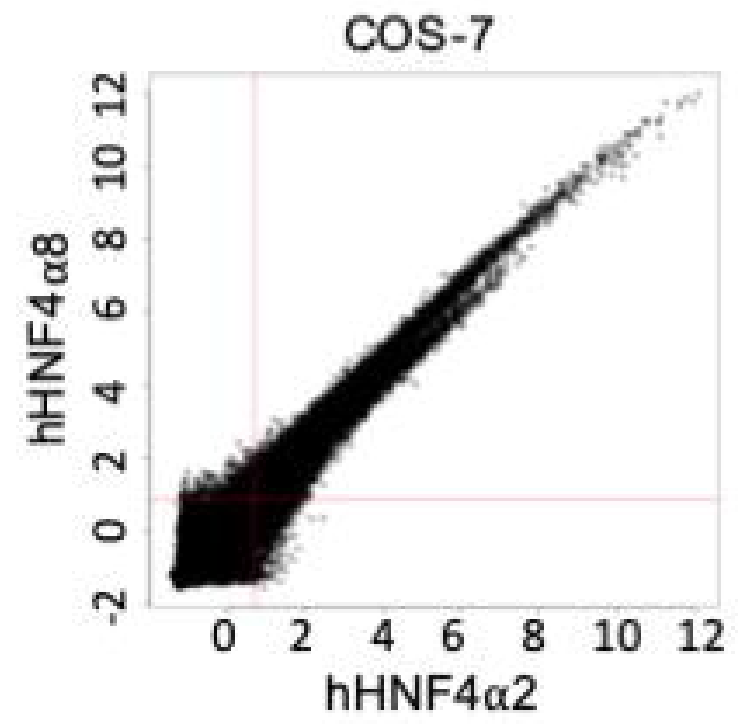

\begin{tabular}{lr}
\multicolumn{1}{c}{ Source } & \#Seq \\
\hline HNF4 $\alpha$ ChIP-seq & $-25,000$ \\
DR1 Motifs & $-17,250$ \\
DR2 Motifs & -500 \\
Random & 900 \\
Total & $-44,000$
\end{tabular}

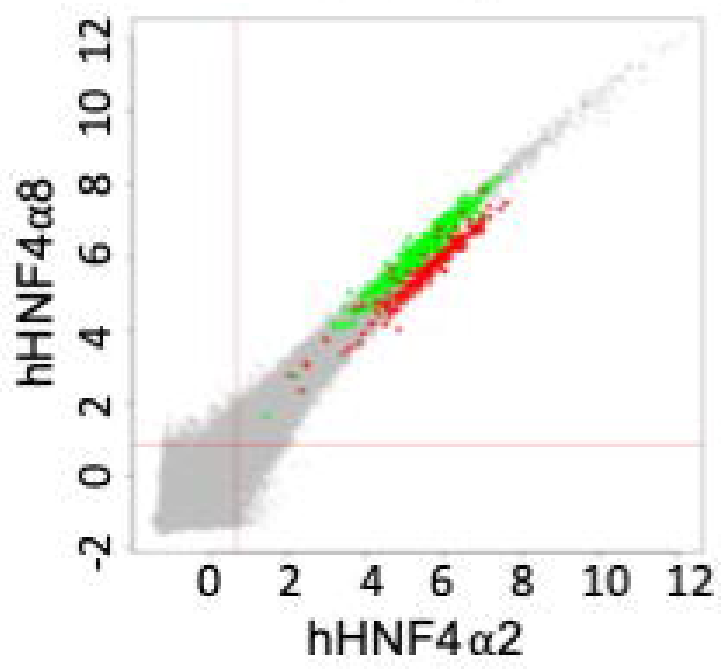

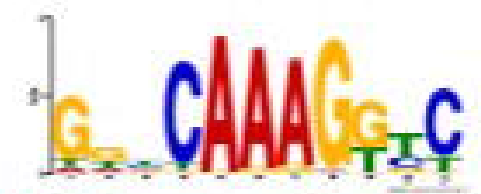

HNF4a Specific Motif

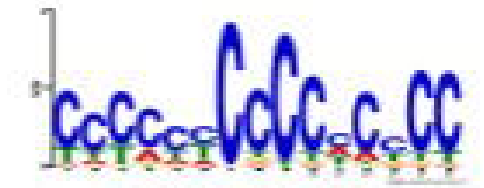

KLF Motif
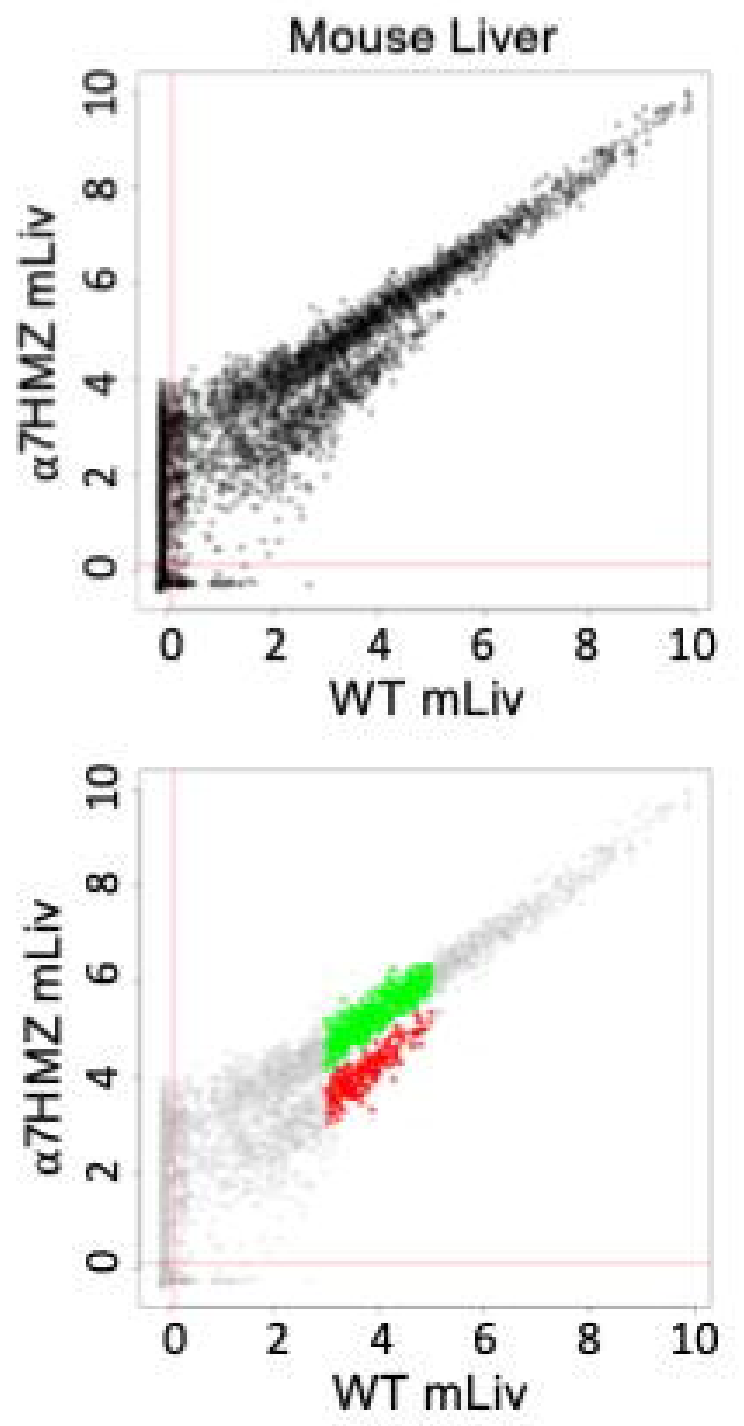
A
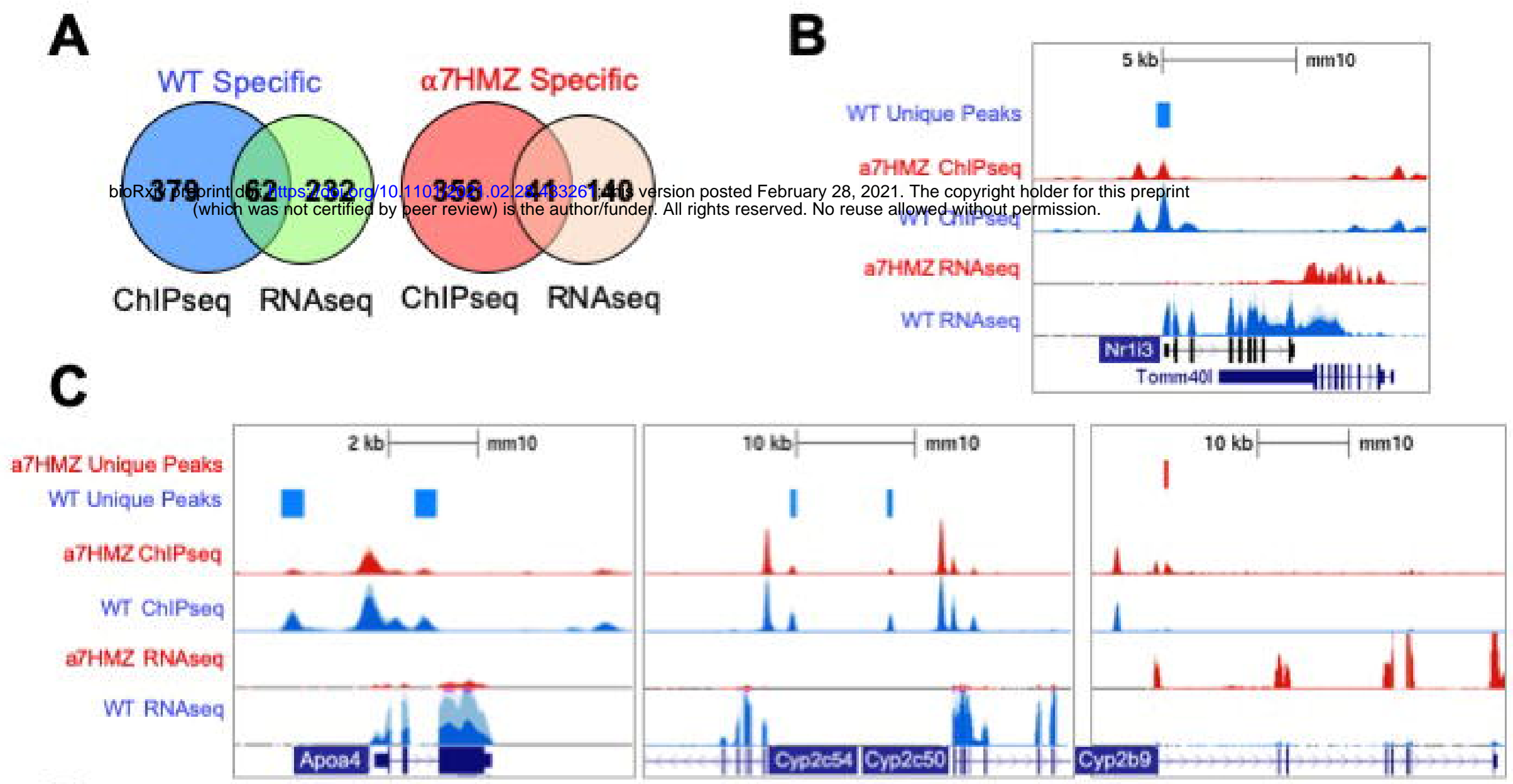

D
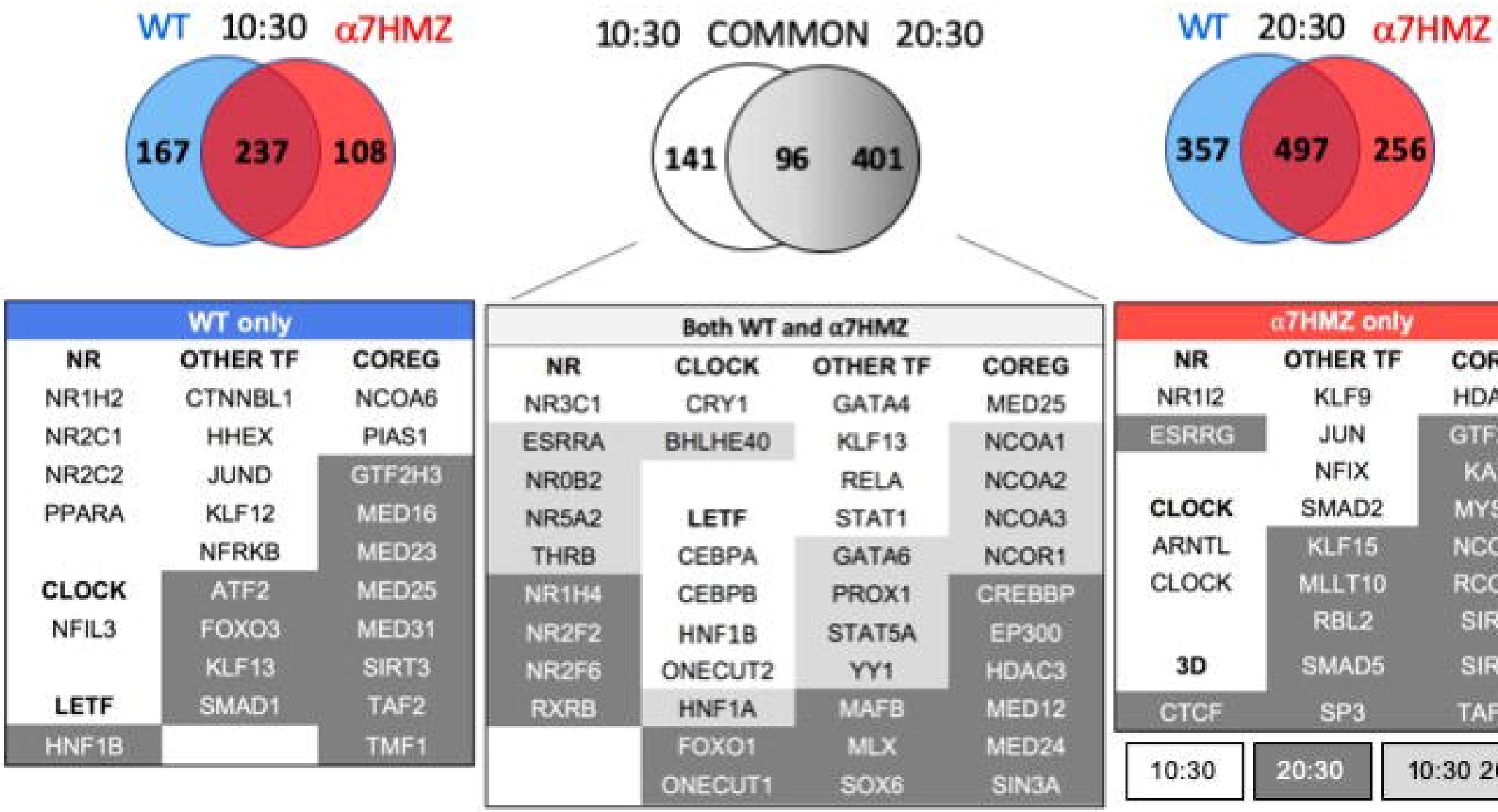

\begin{tabular}{|c|c|c|}
\hline \multicolumn{3}{|c|}{ a7HMz only } \\
\hline NR & OTHER TF & COREG \\
\hline NR1/2 & KLF9 & HDAC2 \\
\hline ESRRG & JUN & GTF2E1 \\
\hline & NFIX & KAT7 \\
\hline CLOCK & SMAD2 & MYSTR \\
\hline ARNTL & KLF15 & NCOA5 \\
\hline CLOCK & MLLT10 & RCOR1 \\
\hline & RBL2 & SIRT1 \\
\hline 3D & SMAD5 & SIRT2 \\
\hline CTCF & SP3 & TAF9B \\
\hline $10: 30$ & $20: 30$ & $3020: 30$ \\
\hline
\end{tabular}


Deans_Fig6

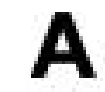

\section{Circadian Transcripts}

Arntl Clock
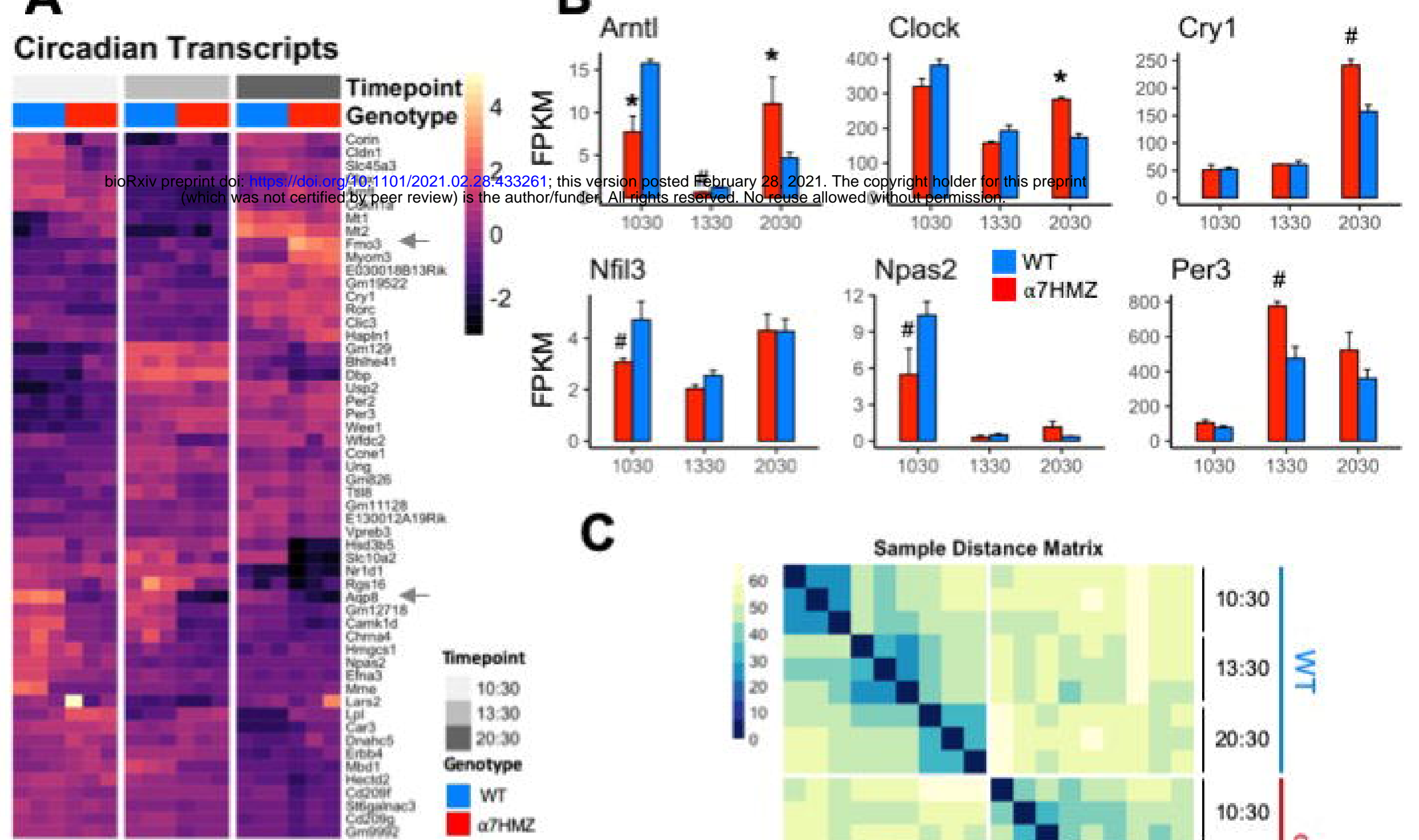

\section{Clock Machinery}
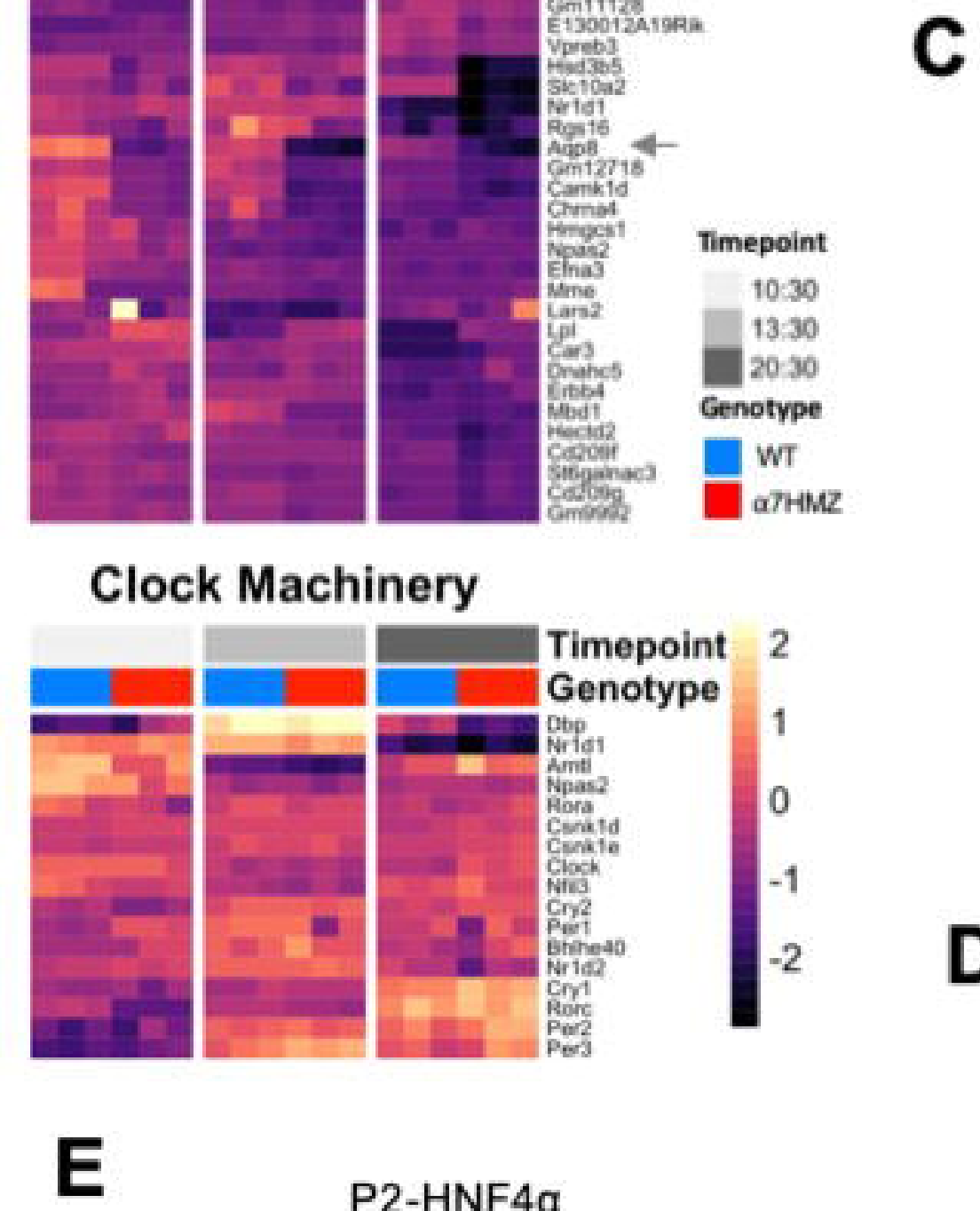

D
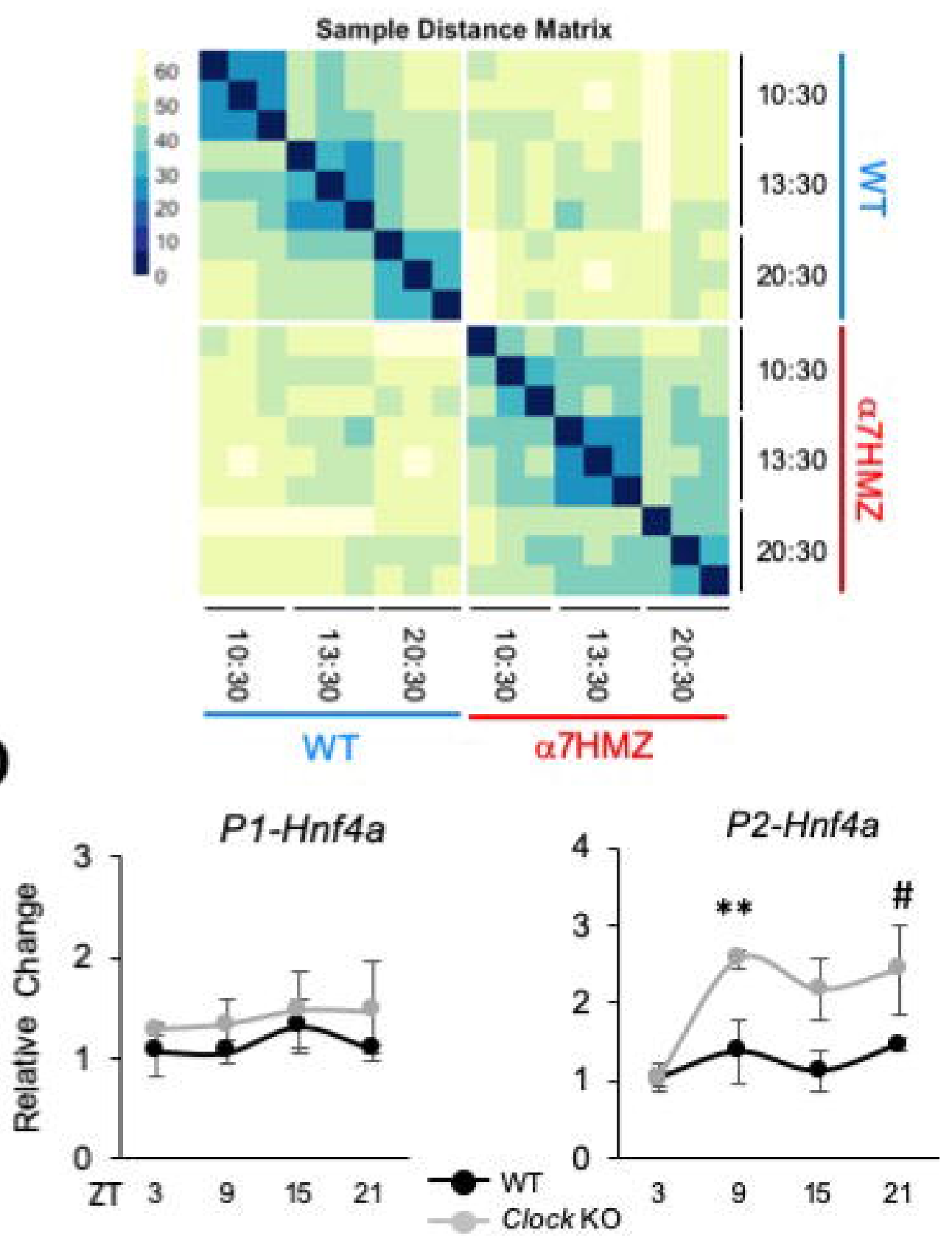
A

B

$1^{\circ}$ Metabolites Complex Lipids

Glucose Pyruvate Citric Acid

$\beta$-hydroxybutyric

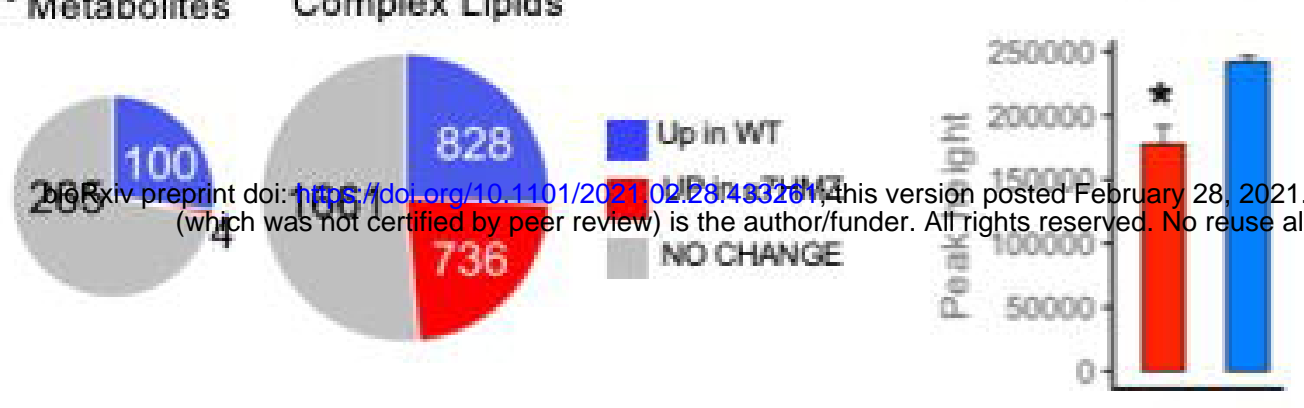

Triglycerides Diglycerides Acylcarnitines

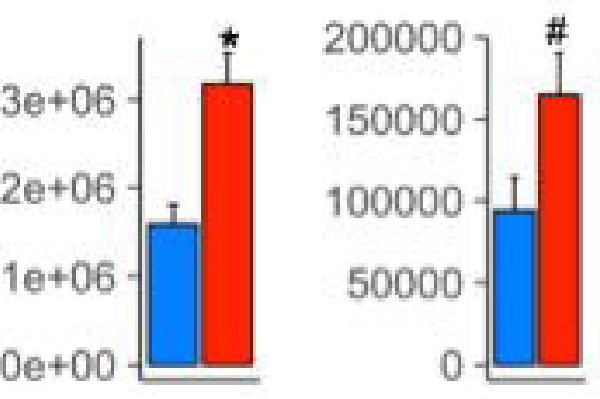

D

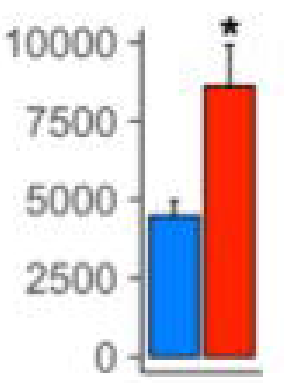

Fed vs Fasted:

WT $\quad 673$

a7HMZ $\quad 531$

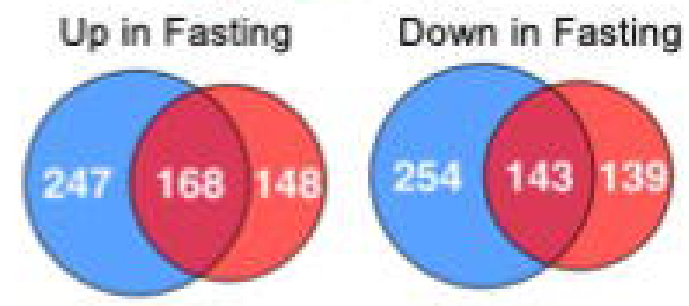

WT $\alpha$ $\alpha 7 \mathrm{HMZ}$ acid

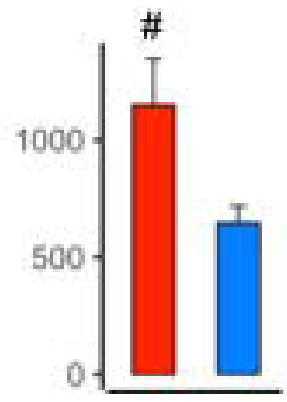

Liver:Body wt

E

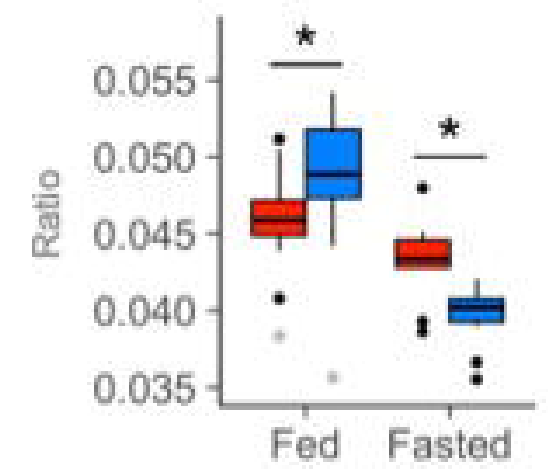

$\mathbf{F}$

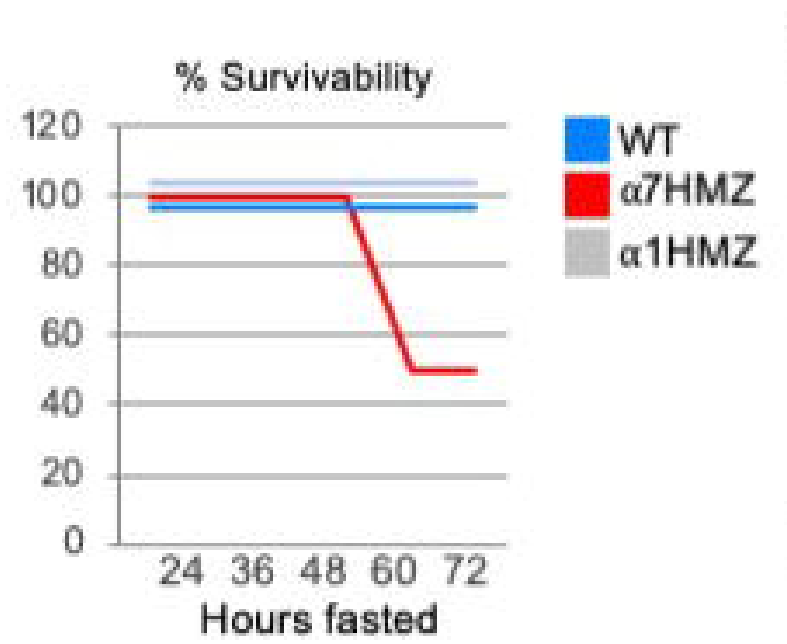

H

Gluconeogenesis

Homeostasis

G 60 hr fast

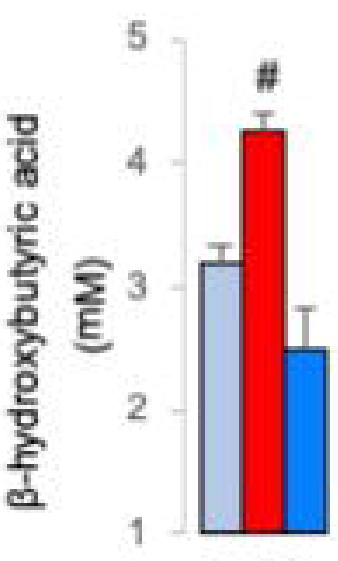

ZT23

Ketogenesis
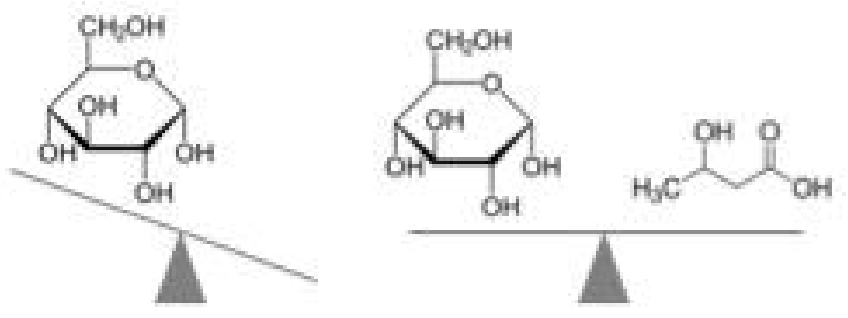

$\mathrm{P} 1-\mathrm{HNF} 4 \alpha$

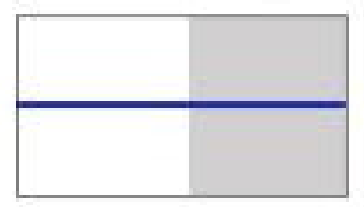

ZT9 ZT21
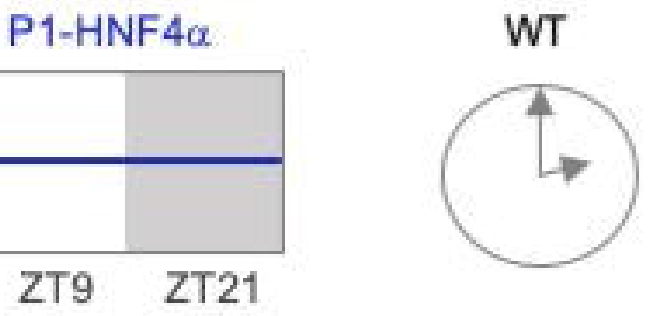

Orom

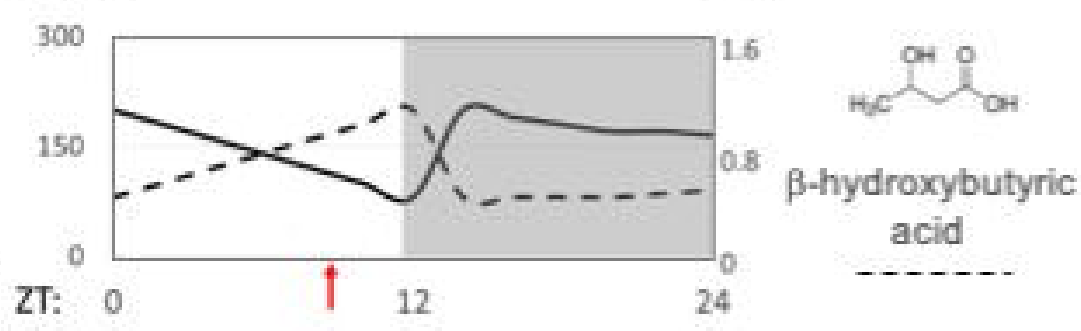

P2-HNF4a.

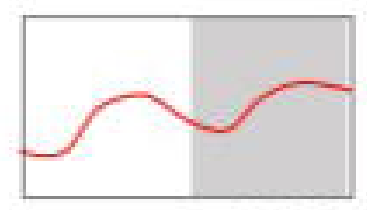

ZT9 ZT21

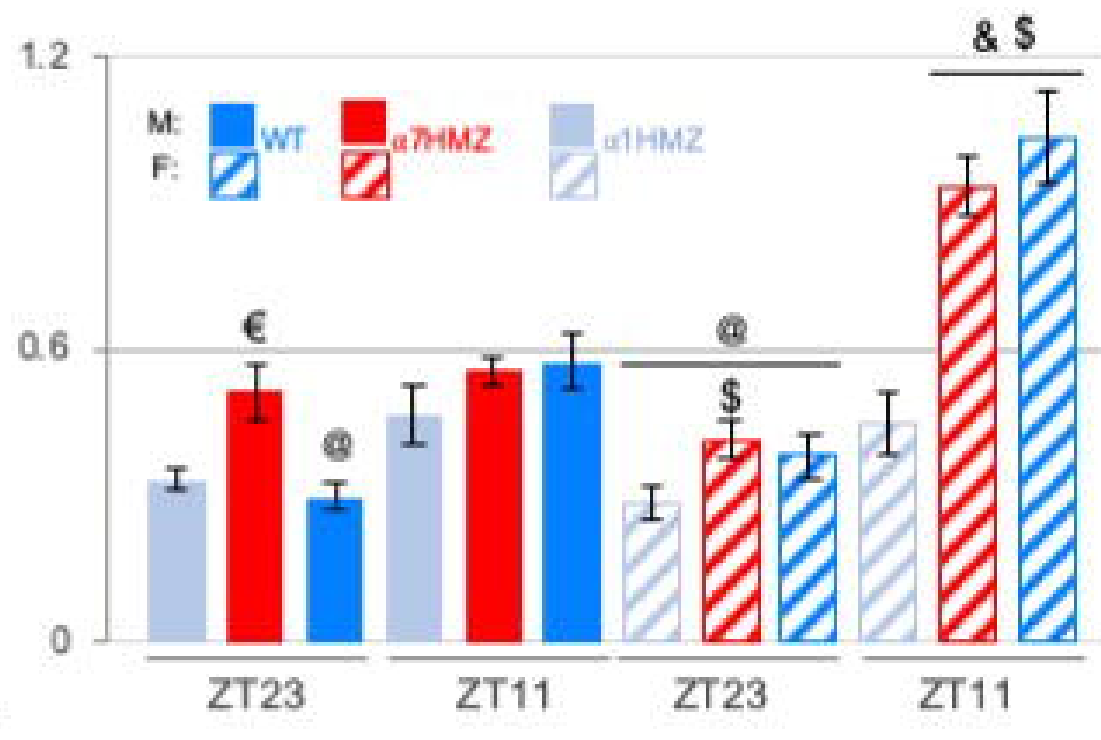

Differential co-regulator recruitment
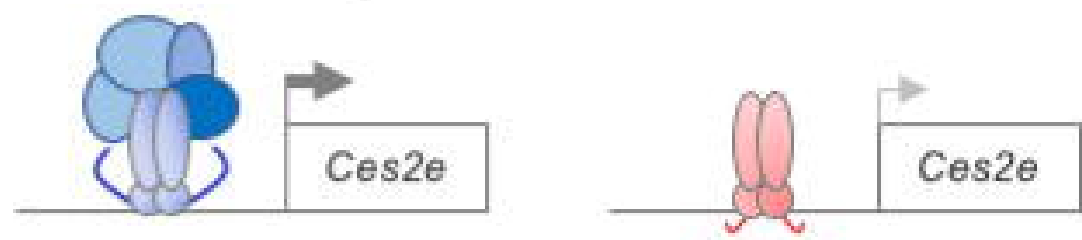

Differential chromatin binding
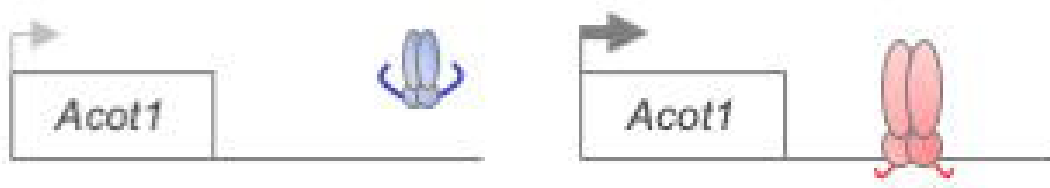

Differential TF recruitment/interaction

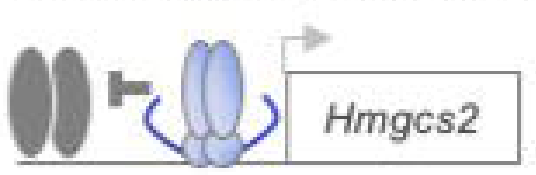

Cyp2b13 